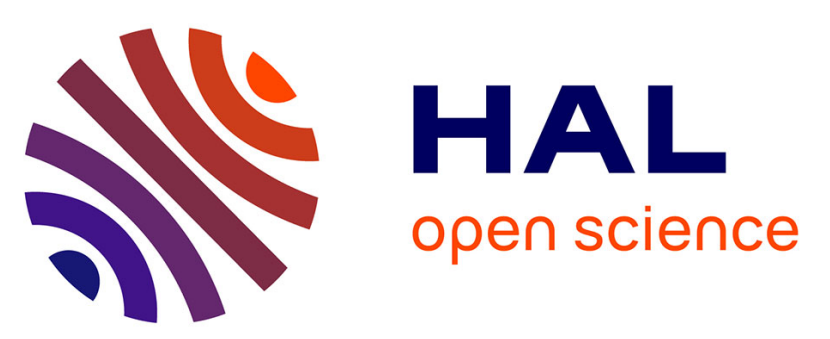

\title{
Iterative Photoinduced Chain Functionalization as a Generic Platform for Advanced Polymeric Drug Delivery Systems
}

\author{
Assala Al Samad, Audrey Bethry, Olga Janouskova, Jéremie Ciccione, \\ Christiane Wenk, Jean-Luc Coll, Gilles Subra, Tomáš Etrych, Fawaz El Omar, \\ Youssef Bakkour, et al.
}

\section{To cite this version:}

Assala Al Samad, Audrey Bethry, Olga Janouskova, Jéremie Ciccione, Christiane Wenk, et al.. Iterative Photoinduced Chain Functionalization as a Generic Platform for Advanced Polymeric Drug Delivery Systems. Macromolecular Rapid Communications, 2018, 39 (3), pp.1700502. 10.1002/marc.201700502 . hal-02387415

\section{HAL Id: hal-02387415 \\ https://hal.umontpellier.fr/hal-02387415}

Submitted on 29 Nov 2019

HAL is a multi-disciplinary open access archive for the deposit and dissemination of scientific research documents, whether they are published or not. The documents may come from teaching and research institutions in France or abroad, or from public or private research centers.
L'archive ouverte pluridisciplinaire HAL, est destinée au dépôt et à la diffusion de documents scientifiques de niveau recherche, publiés ou non, émanant des établissements d'enseignement et de recherche français ou étrangers, des laboratoires publics ou privés. 


\section{Iterative Photoinduced Chain Functionalization as a Generic Platform for}

\section{Advanced Polymeric Drug Delivery Systems}

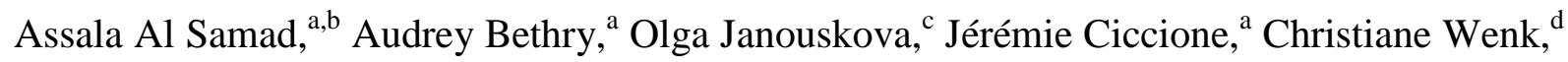
Jean-Luc Coll, ${ }^{\mathrm{d}}$ Gilles Subra, ${ }^{\mathrm{a}}$ Tomas Etrych, ${ }^{\mathrm{c}}$ Fawaz El Omar, ${ }^{\mathrm{b}}$ Youssef Bakkour, ${ }^{\mathrm{b}}$ Jean Coudane, ${ }^{\mathrm{a}}$ Benjamin Nottelet*a

\footnotetext{
${ }^{a}$ Institut des Biomolécules Max Mousseron (IBMM UMR 5247), Université Montpellier, CNRS, ENSCM, Faculté de Pharmacie, 15, avenue Charles Flahault BP14491, 34093

Montpellier cedex 5, France E-mail: benjamin.nottelet@umontpellier.fr

${ }^{b}$ Laboratory of applied Chemistry, Faculty of Science III, Lebanese University, P.O. Box 826,Tripoli, Lebanon

${ }^{\mathrm{c}}$ Institute of Macromolecular Chemistry, Czech Academy of Sciences, Heyrovského nám. 2, 16206 Prague, Czech Republic.

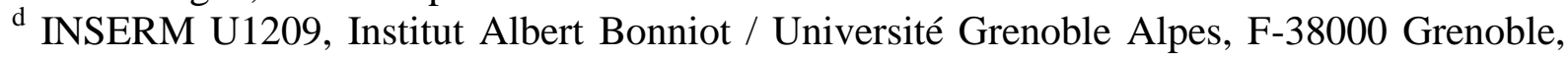
France
}

Advanced drug delivery systems (DDS) are easily designed following a photoiterative strategy. Multifunctional polymers are obtained by coupling building blocks of interest to an alkynated PCL platform via an efficient thiol-yne photoaddition. Fine tuning over the design is achieved as illustrated with targeting and enzyme-responsive DDS.

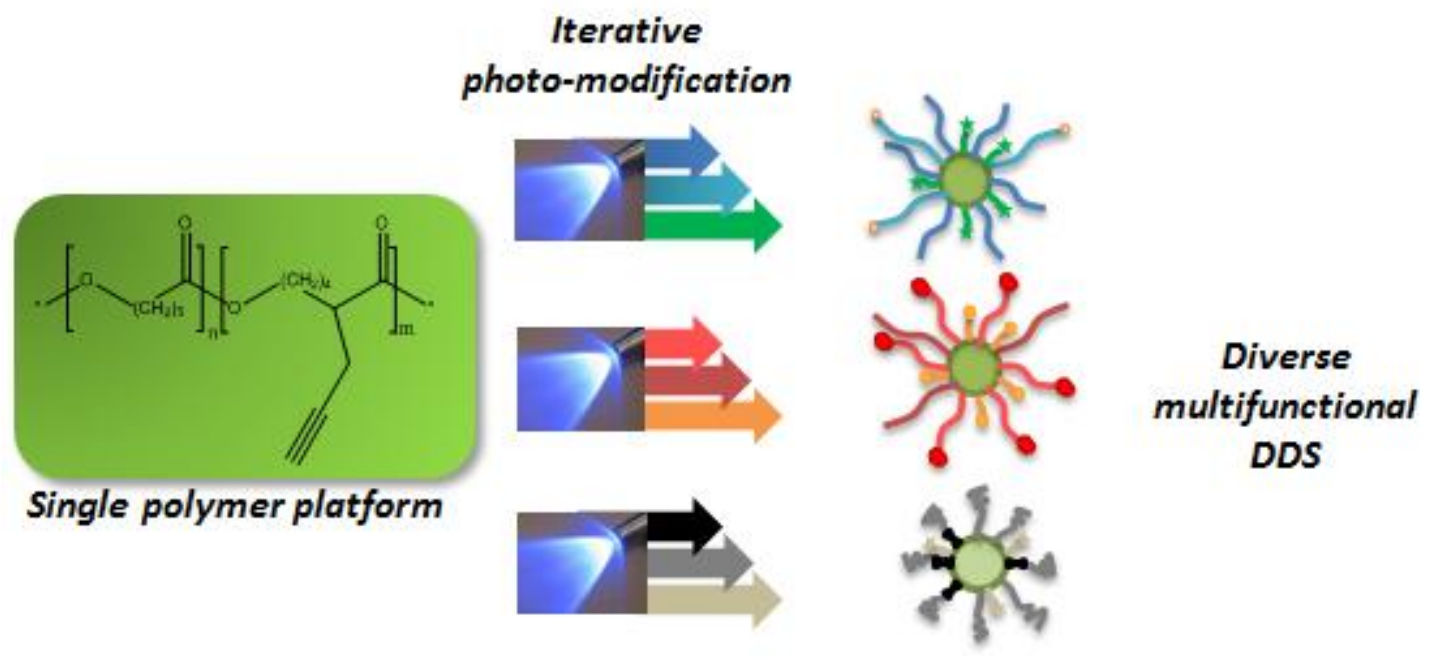




\section{Introduction}

Efficient and simple modulation of DDS surfaces is highly desirable for enhanced in vivo efficacy. It is in particular the case for cancer treatments where DDS should demonstrate highly prolonged circulation time in blood, increased accumulation in tumor and sufficient internalization into cancer cells. These multiple requirements are still the driving force for nanovectors research and the development of methodologies allowing the multifunctionalization of polymers and biomaterial surfaces is therefore a key point for the translation of advanced DDS from bench to patient. ${ }^{[1]}$ However, despite a tremendous variety of smart DDS described in literature, very few are close to clinic, with only the simplest systems finding their way to the market like the PEGPLA-based Genexol® ${ }^{[2]}$ This example paves the way to future products and confirms the potential of polyester-based DDS. It highlights however one major problem, which is the difficulty to make advanced DDS a marketable reality due to various factors. Firstly, the low gain of efficiency reported for the more advanced targeting DDS compared to the classical DDS using EPR effect for accumulation. ${ }^{[3]}$ Here, systematic and more transversal approaches should allow to overcome this pitfall. ${ }^{[4]}$ Secondly, the fact that many actors have to converge to allow such development taking into account industry dynamics, regulation and ethical issues. ${ }^{[5]}$ Last, the difficulty to modify the exiting approved polymers, especially aliphatic polyesters, to efficiently manufacture such advanced DDS with reproducibility and cost-effectiveness.

In fact, classical polyesters that are FDA-approved for medical devices or drug formulations, like PLA, PGA, PCL and their copolymers, do not exhibit functional groups with exception to the terminal hydroxyl or carboxyl groups. To solve this lack of reactivity, various methods have been implemented including post-polymerization methods like wet chemistry under mild degrading conditions (aminolysis, hydrolysis) ${ }^{[6]}$ 
or plasma activation, ${ }^{[7]}$ and synthesis of lactones bearing functional groups. ${ }^{[8-10]}$ However, the post-polymerization strategies generally face problems of chain degradation and limited number of accessible reactive groups, whereas the lactone strategy faces problems of low yield due to multistep reactions and challenging purifications and, depending on the substituent, moderate to low monomer conversion and polymerization degrees. Another problem resides in the variety of chemistries, and therefore reacting groups, that may be required to efficiently generate multifunctional polymeric vectors. There is therefore a challenge to yield advanced DDS (i) based on cheap, stable and versatile polymeric platforms on one hand, and (ii) based on simple and industry-transferable methodologies. Considering these aspects, our group previously reported on the synthesis of a multi-alkynated PCL (PCL-yne) following a post-polymerization strategy that presented the advantage of yielding in one step PCLyne with $c a$. $10 \%$ mol of propargylated units at a multigram scale and in one day. ${ }^{[11]}$ This stable macrosynthon was advantageously used to prepare interpenetrating networks and amphiphilic copolymers using thiol-yne chemistry. ${ }^{[11-13]}$

Herein, we report on a simple method to synthesize multifunctional polymers for advanced DDS by an original iterative procedure that consists of the sequential coupling of building blocks of interest to PCL-yne via a single thiol-yne photoaddition procedure (Scheme 1). 


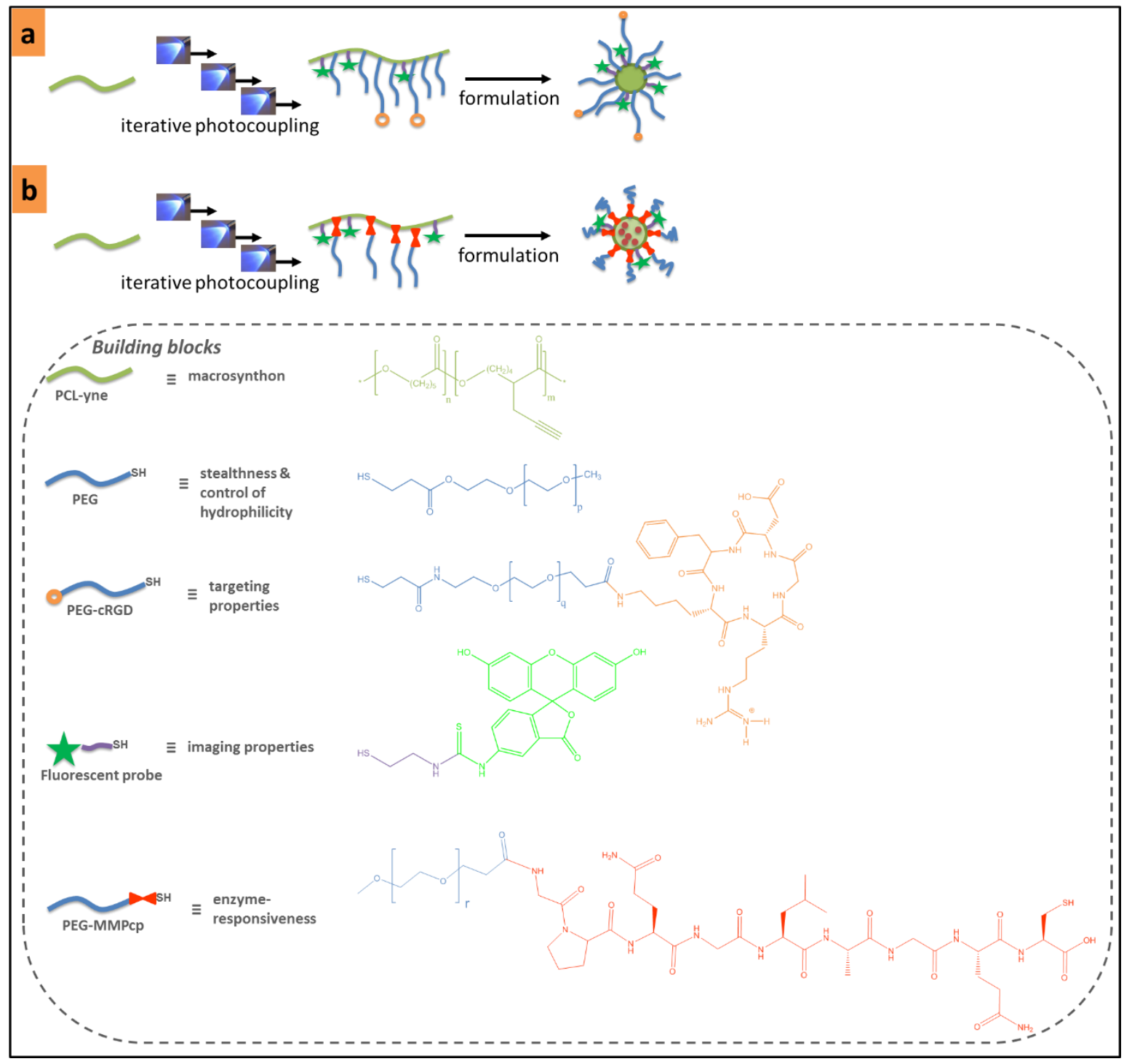

Scheme 1. Illustration of (a) targeting DDS and (b) enzyme-responsive DDS design through iterative photoinduced functionalization of a PCL platform with selected building blocks.

\section{Results and Discussion}

In this work, we chose to apply our synthetic strategy to PCL-g-PEG graft copolymers to demonstrate the control offered by the iterative thiol-yne photoaddition to finely tune the composition. In the frame of DDS, such copolymers present the advantage of having lower critical micellar concentrations (CMC) over their linear analogues because of the side chains reducing their mobility and of their higher polydispersity. ${ }^{[13,14]}$ As a proof of concept, the building blocks bearing free thiol groups were selected i) to allow a control over the 
hydrophilicity of the system, ii) to impart targeting properties or enzyme-responsiveness and iii) to impart imaging/follow-up properties (Scheme 1). In more details, PEG was chosen as hydrophilic side chains, owing to its non-toxicity, biological inertness, and its well-known ability to confer stealthness to nanovectors. ${ }^{[15]}$ PEG-cRGD was chosen as targeting group owing to the high binding affinity of cRGD oligopeptide (Scheme S1, SI) to tumor cells overexpressing RGD-integrin $\alpha v \beta 3^{[16]}$ in prostate, skin, ovary, lung, kidney and breast cancers. ${ }^{[17,18]}$ Tumor cells being known to overexpress matrix metalloproteinases (MMP), ${ }^{[19]}$ PEG-MMPcp (PEG bearing a MMP cleavable peptide, Scheme 1) was chosen as an alternative building block. The aim was to get improved drug release from DDS at the vicinity or in cells overexpressing $\mathrm{MMPs}^{[20]}$ and to promote cellular uptake thanks to the MMPtriggered loss of the sheddable hydrophilic shell. ${ }^{[21]}$ Last, fluorescein was chosen as a fluorescent probe to assess the cellular uptake of the DDS.

For DDS with targeting properties (Scheme 1a), detailed synthetic procedures and a general scheme for the synthesis of the copolymers (Scheme S2, SI) can be found in the provided Supplementary Information. The iterative sequence was as follows. First, heterotelechelic PEG3k chains bearing one cRGD moiety and one free thiol were reacted with PCL-yne. This building block being the more sterically hindered it was the first to be reacted to ensure a more efficient coupling. To evaluate the influence of cRGD grafting density on the cellular binding efficacy two degrees of substitution ( 0.4 or 1.7 cRGD per PCL chain) were targeted. This was achieved by controlling the reaction parameters (details in Table S1, SI). The grafting density was calculated from $1 \mathrm{H}$ NMR analyses by comparison of the peaks at 2.3 ppm and $1.3 \mathrm{ppm}$ of the PCL backbone with the peak at $3.6 \mathrm{ppm}$ of the PEG (Figure S1, SI). In a second iteration, the overall hydrophilicity was tuned thanks to the use of shorter $\mathrm{PEG}_{2 \mathrm{k}}$ chains to guarantee the exposure of $\mathrm{cRGD}$ at the outer surface of the PEG layer on the final nanoobjects. Again, two EG/CL ratios (2.4 and 3.1) enabling 
self-assembly were selected and the targeted compositions were obtained using conditions previously established. ${ }^{[13]}$ At this stage, a copolymer without cRGD and a EG/CL ratio of 3.2 was also prepared as a negative control. Finally, fluorescence was imparted by a final functionalization with a cysteamine spacer reacted with FITC. The success and extent of FITC labeling was confirmed by UV/visible spectroscopy. Details on the copolymers composition, molecular weight and dispersity are provided in Table S2 (SI).

To investigate the potential of the PCL-g-(PEG-cRGD) copolymers as DDS, their selfassembly was first assessed using dynamic light scattering (DLS) measurements (Table S3 and Figure S3, SI). For copolymers having EG/CL $=2.3-2.4$, the intensity size distribution showed a bimodal behavior with a first mean hydrodynamic diameter $\left(D_{H}\right)$ in the range of $25-30 \mathrm{~nm}$ and the second one in the range of 130-150 $\mathrm{nm}$. This second population could be reasonably attributed to the presence of few aggregates. This hypothesis was confirmed when plotting the number size distribution with only one population found with $\mathrm{D}_{H}$ around $20 \mathrm{~nm}$. For more hydrophilic copolymers having $\mathrm{EG} / \mathrm{CL}=3.2$, both distributions were monomodal with size in the range of $35-45 \mathrm{~nm}$ for the intensity distribution and around $16 \mathrm{~nm}$ for the number distribution. The efficacy of our approach to simply yield tunable targeting DDS was then demonstrated by following the cellular binding and uptake of PCL-g-(PEG-cRGD) nanoaggregates as a function of their cRGD content (Figure 1). 


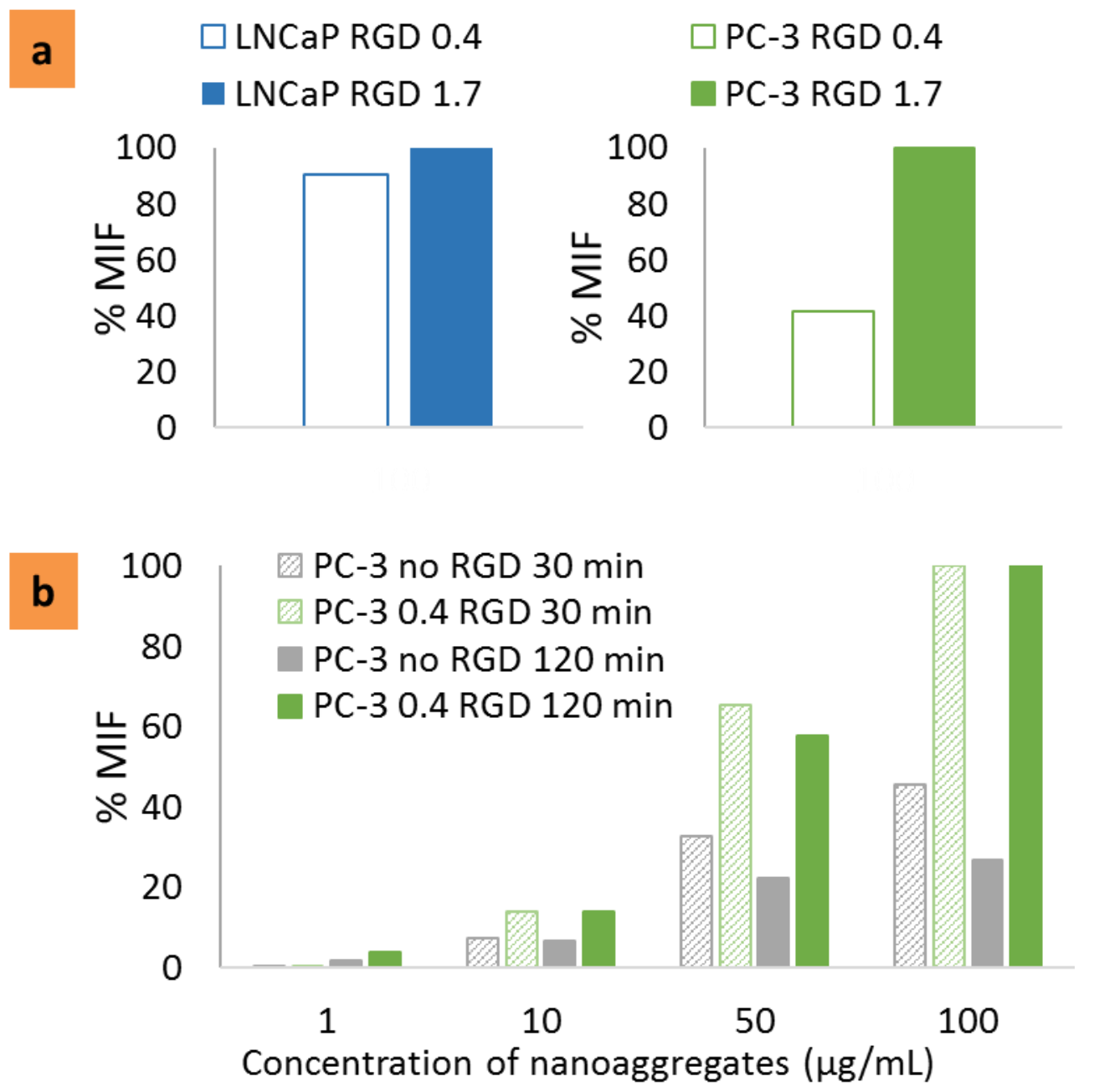

Figure 1. Evaluation of cellular uptake of PCL-g-(PEG-cRGD) copolymers as a function of the content of RGD moieties and of the level of $\alpha v \beta 3$ integrin expression (high for PC-3 cell line vs. low for LNCaP cell-line), with (a) uptake of PCL-g-(PEG $\left.\mathrm{P}_{2.4}-\mathrm{CRGD}_{1.7}\right)$ and PCL-g-(PEG $\left.{ }_{2.4}-\mathrm{CRGD}_{0.4}\right)$ in LNCaP and PC-3 cell-lines after 2 hours incubation (concentration of nanoaggregates $100 \mu \mathrm{g} / \mathrm{mL}$, for each cell line the highest MIF value was used as the $100 \% \mathrm{MIF}$ and other values were calculated accordingly) and (b) uptake of PCL-gPEG $_{3.2}$ and PCL-g-(PEG 3.1 -cRGD $\left.{ }_{0.4}\right)$ in PC-3 cell-line after 0.5 and 2 hours incubation. (Data are expressed as percentage normalized with respect to the highest median intensity of fluorescence for each time point)

FITC-labeled PCL-g-(PEG-cRGD) were incubated with two human prostate adenocarcinoma cell lines. PC-3 were selected as $\alpha v \beta 3$ integrin high expression cell line, and compared to the LNCaP as $\alpha v \beta 3$ integrin low expression cell line. ${ }^{[22,23]}$ For comparison purposes, nanoaggregates with the same EG/CL ratio and with similar 
sizes have been used (Table $\mathbf{S 3}$ entries 1 and 3, SI) and results of fluorescenceactivated cell sorting (FACS) analysis were expressed as percentage of median intensity of fluorescence (MIF) normalized with respect to FITC content. As expected, for the two levels of cRGD no difference was observed for the low integrin LNCaP cells (Figure 1a). In contrast, for the PC-3 cell-line an improved uptake of the nanoaggregates was obtained for higher cRGD content with up to $60 \%$ higher uptake at a concentration of $100 \mu \mathrm{g} / \mathrm{mL}$ when increasing the cRGD ratio from 0.4 to 1.7 . In another experiment, shorter incubation time and low content of cRGD (0.4) were used to account for the cRGD effect that is expected to induce fast adhesion. Nanoaggregates with low or no cRGD content (Table S3 entries 2 and 4, SI) were incubated at concentrations ranging from 1 to $100 \mu \mathrm{g} / \mathrm{mL}$ with $\alpha \mathrm{v} \beta 3$ integrin positive PC-3 cells. After 30 minutes a clear impact was observed even at low concentrations of nanoaggregates and low content of cRGD with twice higher cellular uptake for PCL- $g$ $\left(\mathrm{PEG}_{3.1}-\mathrm{cRGD}_{0.4}\right)$ compared to its counterpart (PCL- $\left.g-\mathrm{PEG}_{3.2}\right)$ at all concentrations (Figure 1b). This trend was further confirmed and reinforced after 2 hours of incubation with up to 4 times higher uptake for the cRGD functionalized copolymer. This set of results, although preliminary, confirms the availability of the cRGD at the surface of the nanoaggregates for an improved cellular uptake. It also confirms the potential of the iterative photo thiol-yne strategy as a means to efficiently and easily modify copolymers to prepare targeting vectors with enhanced biological outcome.

To further illustrate the versatility of our iterative approach, and as a second proof of concept, this simple iterative procedure was used to yield DDS with enzymeresponsive properties. In fact, recent drug delivery strategies involve the use of matrix metalloproteinase cleavable oligopeptides as linkers for PEG-based block copolymers. Such DDS, while presenting the advantages imparted by their PEG shell (stability, 
stealth properties), show improved cellular uptakes following the removal of their PEG corona in MMP rich environment as a consequence of an increase of their hydrophobicity that enhances interaction with cells and cell compartments. ${ }^{[21]}$ In this work DDS with MMP-cleavable PEG shells (Scheme 1b) were easily obtained in a two-step iterative procedure by using the same fluorophore but replacing the targeting PEG-cRGD by PEG $_{0.75 k}$ chains end-functionalized with the MMPcp GPQGLAGQC that presents a free thiol on the $\mathrm{C}$ residue available for thiol-yne photoaddition (detailed synthetic procedures and structure provided in SI, Scheme S1and Scheme S3). This sequence is a substrate for MMPs overexpressed in many cancers and is selectively cleaved by MMP-9 between the G and L residues. ${ }^{[24]}$ In opposition to targeting DDS, FITC labeling was chosen as a first step to minimize the use of PEGGPQGLAGC derivative in this linear synthetic strategy. PCL-g-(MMPcp-PEG) with various contents of cleavable PEG side chains were then obtained by changing the initial ratio MMPcp-PEG/DMPA/PCL in the thiol-yne photoaddition (Table S4, SI). Copolymers composition was calculated from ${ }^{1} \mathrm{H}$ NMR analyses as previously discussed for the targeting DDS (Figure S2, SI). Copolymers had EG/CL equal to 0.4, 0.6 and 0.7 corresponding to 2.7, 4.0 and 4.7 grafted MMPcp-PEG chains per PCL backbone, respectively. Owing to their relative hydrophobicity, these PCL-g-(MMPcpPEG) were co-formulated with a more hydrophilic but not cleavable PCL-g-PEG $\left(\mathrm{PEG}_{2 \mathrm{k}}\right.$ side chains, $\left.\mathrm{EG} / \mathrm{CL}=4.2\right)$ at a $50 \mathrm{wt} \%$ ratio to reach $\mathrm{EG} / \mathrm{CL}$ ratios of $1.6,1.8$ and 1.9, respectively (Table S5, SI) thus allowing the preparation of curcumin-loaded nanoaggregates with drug loadings ranging from 8 to $12 \mathrm{wt} \%$. The size of the nanoaggregates was assessed using DLS measurements. The intensity size distribution showed $\mathrm{D}_{H}$ in the range of $100-270 \mathrm{~nm}$. Again, these large sizes were attributed to the presence of aggregates, as confirmed by the number size distribution showing $\mathrm{D}_{H}$ in the range of 7-15 nm (Table S5 and Figure S4, SI). The cytotoxicity of curcumin- 
loaded nanoaggregates was then assessed. Following control experiments that confirmed the absence of toxicity of non-loaded nanoaggregates (Figure S5 and S6, SI), HEK293- $\beta 3$ cells expressing MMP-2 and MMP-9 ${ }^{[16]}$ were used to study the behavior and cytotoxicity of the curcumin-loaded sheddable nanoaggregates as a function of the content of MMPcp-PEG cleavable chains. For comparison purposes, nanoaggregates with similar EG/CL ratio and sizes have been used (Table S5, SI) In a first experiment, the internalization of sheddable (S) vs. non-sheddable (NS) nanoaggregates was assessed by fluorescence microscopy. Nanoaggregates NS and S4.0 were incubated for $48 \mathrm{~h}$ with HEK293- $\beta 3$ cells.
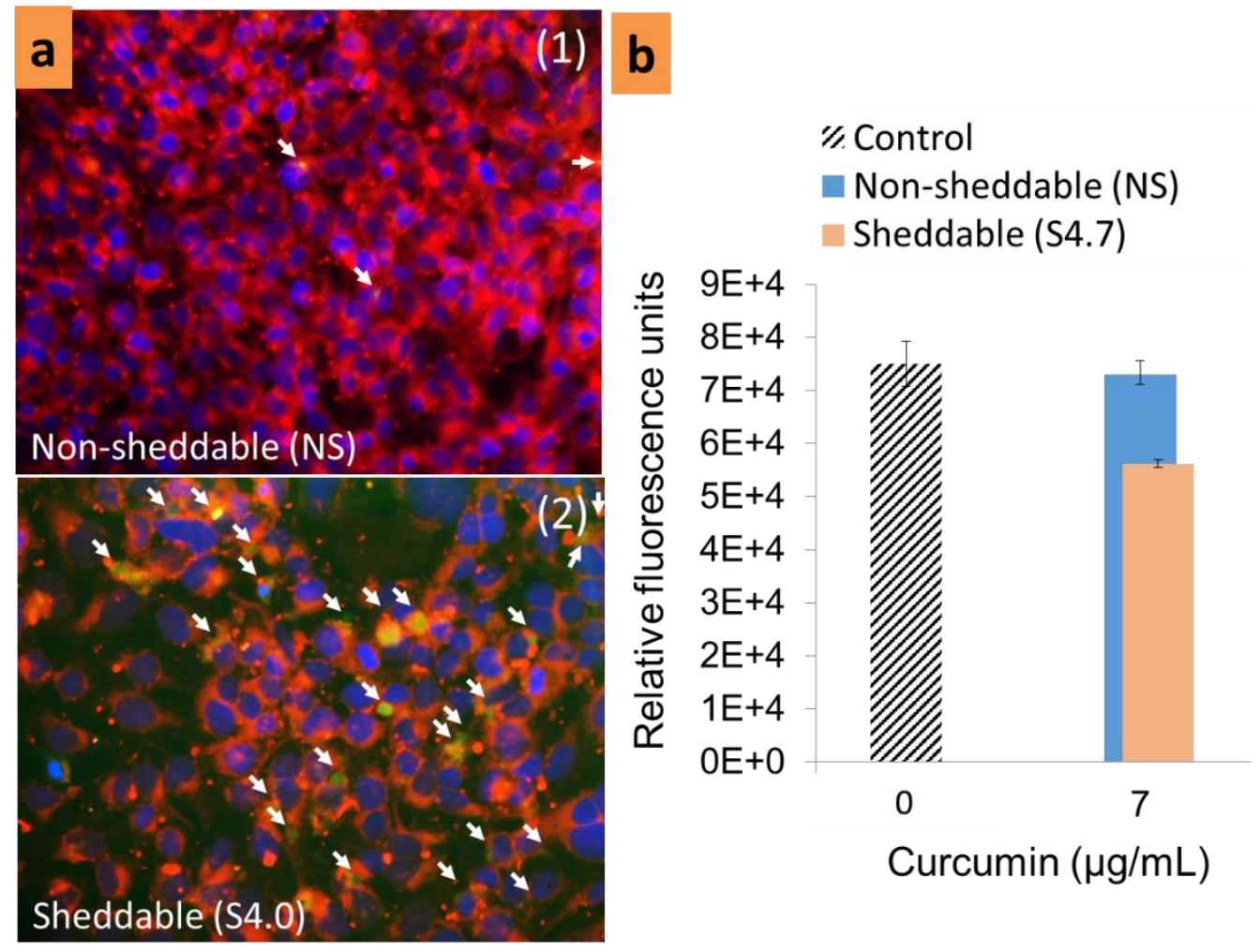

Figure 2. Compared in vitro cellular uptake and cytotoxicity of sheddable vs. non- sheddable nanoaggregates, with (a) in vitro HEK293- $\beta 3$ cellular uptake of fluorescently labeled nanoaggregates after $48 \mathrm{~h}$ with (1) non-sheddable nanoaggregates (NS, Table S5, SI) and (2) sheddable nanoaggregates (S4.0, Table S5, SI) (white arrows point out the fluorescent areas) and (b) in vitro cytotoxicity of curcumin-loaded non-sheddable vs. sheddable nanoaggregates (NS vs. S4.7, Table S5, SI) (48 hours incubation; control corresponds to culture medium without nanoaggregates and without curcumin) 
Very little fluorescence was observed within the cells for the non-sheddable nanoaggregates NS (Figure 2a). In contrast, large areas of green fluorescence, corresponding to the internalized nanoaggregates, were visible for the sheddable nanoaggregates S4.0. This higher internalization was then correlated with cytotoxicity. After 24 hours, no difference in cytotoxicity was observed for all copolymers irrespective of the presence and content of MMPcp-PEG chains (Figure S7, SI), as consequence of a very limited cleavage of MMPcp-PEG chains at this time point. However, after 48 hours, whereas absence of toxicity was witnessed for the nonsheddable nanoaggregates compared to the control, toxicity was obtained for the sheddable ones (Figure $\mathbf{2 b}$ ) in accordance with internalization observations. Additionally, it was confirmed that toxicity increased with increasing content of cleavable MMPcp-PEG chains (Figure S8, SI). This set of results confirms the importance of PEG chains cleavage by the MMPs for an improved cellular uptake and subsequent cellular toxicity. In fact, in the hypothesis of a full removal of MMPcpPEG chains from the sheddable nanoaggregates S4.7 the EG/CL ratio theoretically decreases from 1.9 to 1.4 , which make them more hydrophobic than the non-sheddable nanoaggregates NS $(\mathrm{EG} / \mathrm{CL}=2)$. This higher hydrophobicity leads to an easier internalization and therefore higher cytotoxicity, in accordance with previously reported studies. ${ }^{[13,21]}$ Further experiments, including in vivo evaluation of the presented DDS, will be performed in the future to confirm these data.

\section{Conclusions}

In summary, this work reports the preparation of multifunctional copolymers thanks to an iterative photoinduced functionalization. A fine control over the sequence of functionalization and over the number of functional groups that can be introduced is made possible by a simple 
control of the reaction parameters. Based on the two proofs of concept reported in this communication, namely integrin-targeting and sheddable copolymers, it is our belief that the simple approach described here could be applied to various polymeric systems. It opens therefore new routes towards tunable advanced DDS that could be easily, and in a controlled manner, decorated with biologically relevant functionalities for improved biological outcomes.

\section{Supporting Information}

Supporting Information is available from the Wiley Online Library or from the author

Acknowledgements: This work was supported by the Azm \& Saade Association of Lebanon and by the Ministry of Education, Youth and Sports of the Czech Republic within the National Sustainability Program I (Project POLYMAT LO1507 and BIOCEV-FAR LQ1604). Authors wish to thank the Synbio 3 platform for the peptides as well as Stéphane Déjean and Sylvie Hunger for analyses.

Keywords: functionalization of polymers, photochemistry, polyesters, stimuli-responsive polymers, drug delivery systems

[1] H. Cabral, K. Kataoka, J. Control.Release 2014, 190, 465.

[2] V. Weissig, T. K. Pettinger, N. Murdock, Int. J. Nanomed. 2014, 9, 4357.

[3] S. Wilhelm, A. J. Tavares, Q. Dai, S. Ohta, J. Audet, H. F. Dvorak, W. C. W. Chan, Nat. Rev. Mater. 2016, 1, 16014.

[4] M. Bjornmalm, M. Faria, F. Caruso, J. Am. Chem. Soc. 2016, 138, 13449.

[5] H. te Kulve, A. Rip, Expert Opin. Drug Deliv. 2013, 10, 611. 
[6] S. G. Wang, W. J. Cui, J. Z. Bei, Anal. Bioanal. Chem. 2005, 381, 547.

[7] T. Desmet, R. Morent, N. De Geyter, C. Leys, E. Schacht, P. Dubruel, Biomacromolecules 2009, 10, 2351.

[8] S. Blanquer, J. Tailhades, V. Darcos, M. Amblard, J. Martinez, B. Nottelet, J. Coudane, J. Pol. Sci., Part A-Polym. Chem. 2010, 48, 5891.

[9] W. W. Gerhardt, D. E. Noga, K. I. Hardcastle, A. J. Garcia, D. M. Collard, M. Weck, Biomacromolecules 2006, 7, 1735.

[10] X. D. Lou, C. Detrembleur, R. Jerome, Macromol. Rapid Commun. 2003, 24, 161.

[11] A. Leroy, A. Al Samad, X. Garric, S. Hunger, D. Noël, J. Coudane, B. Nottelet, RSC Adv. 2014, 4, 32017.

[12] A. Al Samad, Y. Bakkour, C. Fanny, F. El Omar, J. Coudane, B. Nottelet, Polym. Chem. 2015, 6, 5093.

[13] A. Al Samad, A. Bethry, E. Koziolova, M. Netopilik, T. Etrych, Y. Bakkour, J. Coudane, F. El Omar, B. Nottelet, J. Mater. Chem. B. 2016, 4, 6228.

[14] C.-L. Lo, C.-K. Huang, K.-M. Lin, G.-H. Hsiue, Biomaterials 2007, 28, 1225.

[15] L. Tang, X. Yang, Q. Yin, K. Cai, H. Wang, I. Chaudhury, C. Yao, Q. Zhou, M. Kwon, J. a. Hartman, I. T. Dobrucki, L. W. Dobrucki, L. B. Borst, S. Lezmi, W. G. Helferich, a. L. Ferguson, T. M. Fan, J. Cheng, Proc. Natl. Acad. Sci. 2014, 111, 15344.

[16] C. H. F. Wenk, V. Josserand, P. Dumy, J.-L. Coll, D. Boturyn, Org. Biomol. Chem. 2013, 11,448 .

[17] K. Mulgrew, K. Kinneer, X.-T. Yao, B. K. Ward, M. M. Damschroder, B. Walsh, S.-Y. Mao, C. Gao, P. a. Kiener, S. Coats, M. S. Kinch, D. a. Tice, Mol. Cancer Ther. 2006, 5, 3122.

[18] A. Taherian, X. Li, Y. Liu, T. a. Haas, BMC Cancer 2011, 11, 293. 
[19] A. Merdad, S. Karim, H.-J. Schulten, A. Dallol, A. Buhmeida, F. Al-Thubaity, M. A. Gari, A. G. A. Chaudhary, A. M. Abuzenadah, M. H. Al-Qahtani, Anticancer Res. 2014, 34, 1355.

[20] P. S. Kulkarni, M. K. Haldar, R. R. Nahire, P. Katti, A. H. Ambre, W. W. Muhonen, J. B. Shabb, S. K. R. Padi, R. K. Singh, P. P. Borowicz, D. K. Shrivastava, K. S. Katti, K. Reindl, B. Guo, S. Mallik, Mol. Pharm. 2014, 11, 2390.

[21] R. Li, W. Wu, Q. Liu, P. Wu, L. Xie, Z. Zhu, M. Yang, X. Qian, Y. Ding, L. Yu, X. Jiang, W. Guan, B. Liu, Plos One 2013, 8, 1.

[22] S. Dall'Angelo, Q. Z. Zhang, I. N. Fleming, M. Piras, L. F. Schweiger, D. O'Hagan, M. Zanda, Org. Biomol. Chem. 2013, 11, 4551.

[23] Y. X. Sun, M. Fang, J. H. Wang, C. R. Cooper, K. J. Pienta, R. S. Taichman, Prostate 2007, 67, 61.

[24] J. L. Lauer-Fields, T. Sritharan, M. S. Stack, H. Nagase, G. B. Fields, J. Biol. Chem. 2003, 278, 18140 . 


\section{Captions to figures/schemes}

Scheme 1. Illustration of (a) targeting DDS and (b) enzyme-responsive DDS design through iterative photoinduced functionalization of a PCL platform with selected building blocks.

Figure 1. Evaluation of cellular uptake of PCL-g-(PEG-cRGD) copolymers as a function of the content of RGD moieties and of the level of $\alpha v \beta 3$ integrin expression (high for PC-3 cell line vs. low for LNCaP cell-line), with (a) uptake of PCL-g-(PEG $\left.\mathrm{P}_{2.4}-\mathrm{CRGD}_{1.7}\right)$ and PCL-g-(PEG $2.4-$ CRGD $\left._{0.4}\right)$ in LNCaP and PC-3 cell-lines after 2 hours incubation (concentration of nanoaggregates $100 \mu \mathrm{g} / \mathrm{mL}$, for each cell line the highest MIF value was used as the $100 \% \mathrm{MIF}$ and other values were calculated accordingly) and (b) uptake of PCL-gPEG $_{3.2}$ and PCL-g-(PEG 3.1 -cRGD 0.4$)$ in PC-3 cell-line after 0.5 and 2 hours incubation. (Data are expressed as percentage normalized with respect to the highest median intensity of fluorescence for each time point)

Figure 2. Compared in vitro cellular uptake and cytotoxicity of sheddable vs. non- sheddable nanoaggregates, with (a) in vitro HEK293- $\beta 3$ cellular uptake of fluorescently labeled nanoaggregates after $48 \mathrm{~h}$ with (1) non-sheddable nanoaggregates (NS, Table S5, SI) and (2) sheddable nanoaggregates (S4.0, Table S5, SI) (white arrows point out the fluorescent areas) and (b) in vitro cytotoxicity of curcumin-loaded non-sheddable vs. sheddable nanoaggregates (NS vs. S4.7, Table S5, SI) (48 hours incubation; control corresponds to culture medium without nanoaggregates and without curcumin) 
A simple photochemical iterative procedure tackles the challenge of polymers multifunctionalization for biomedical applications.

Assala Al Samad, ${ }^{\text {a,b }}$ Audrey Bethry, ${ }^{\text {a }}$ Olga Janouskova, ${ }^{\mathrm{c}}$ Jérémie Ciccione, ${ }^{\mathrm{a}}$ Christiane Wenk, ${ }^{\mathrm{d}}$ Jean-Luc Coll, ${ }^{\mathrm{d}}$ Gilles Subra, ${ }^{\mathrm{a}}$ Tomas Etrych, ${ }^{\mathrm{c}}$ Fawaz El Omar, ${ }^{\mathrm{b}}$ Youssef Bakkour, ${ }^{\mathrm{b}}$ Jean Coudane, ${ }^{\mathrm{a}}$ Benjamin Nottelet*a

Iterative Photoinduced Chain Functionalization as a Generic Platform for Advanced Polymeric Drug Delivery Systems

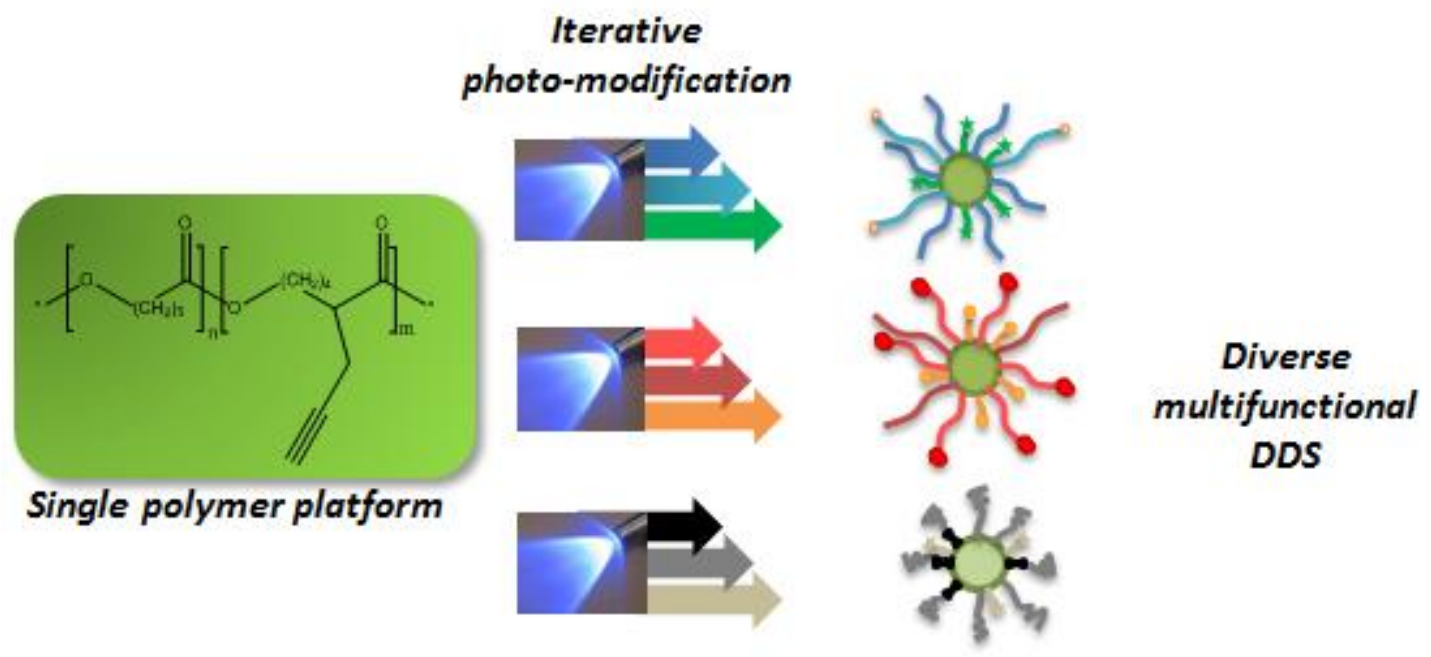




\section{Supporting Information}

\section{Iterative Photoinduced Chain Functionalization as a Generic Platform for}

\section{Advanced Polymeric Drug Delivery Systems.}

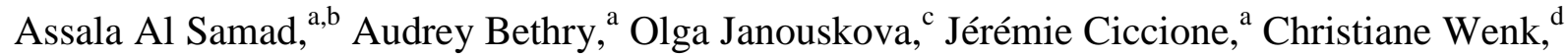

Jean-Luc Coll, ${ }^{\mathrm{d}}$ Gilles Subra, ${ }^{\mathrm{a}}$ Tomas Etrych, ${ }^{\mathrm{c}}$ Fawaz El Omar, ${ }^{\mathrm{b}}$ Youssef Bakkour, ${ }^{\mathrm{b}}$ Jean

Coudane, ${ }^{\mathrm{a}}$ Benjamin Nottelet*a

${ }^{a}$ Institut des Biomolécules Max Mousseron (IBMM UMR 5247), Université Montpellier, CNRS, ENSCM, Faculté de Pharmacie, 15, avenue Charles Flahault BP14491, 34093

Montpellier cedex 5, France

E-mail: benjamin.nottelet@umontpellier.fr

${ }^{\mathrm{b}}$ Laboratory of applied Chemistry (LAC), Faculty of Science III, Lebanese University, P.O.

Box 826,Tripoli, Lebanon

${ }^{\mathrm{c}}$ Institute of Macromolecular Chemistry, Czech Academy of Sciences, Heyrovského nám. 2, 16206 Prague, Czech Republic.

${ }^{\mathrm{d}}$ INSERM U1209, Institut Albert Bonniot / Université Grenoble Alpes, F-38000 Grenoble, France 


\section{Experimental part}

\subsection{Materials}

PCL $(\mathrm{Mn} \approx 45 \mathrm{~kg} / \mathrm{mol}$ ), propargyl bromide (80 wt\% in toluene), lithium diisopropylamide (2M in THF/heptane/ethylbenzene), MeO-PEG-OH (2 kg/mol, noted PEG2k), 2,2-dimethoxy2-phenylacetophenone (DMPA, >99\%), mercaptopropionic acid (MPA,>99\%) cysteamine hydrochlorid (Cys, >98\%), dicyclohexylcarbodiimide (DCC, >99\%), dimethylaminopyridine (DMAP, >99\%), fluorescein 5-isothiocyanate (FITC, > 90\%), $\mathrm{CaSO}_{4}, \mathrm{PBS} 1 \mathrm{X}$ and curcumin from Curcuma longa (Cur, >65\%) were purchased from Sigma-Aldrich (St-Quentin Fallavier, France). N-N-diisopropylethylamine (DIPEA >99.5\%) was obtained from Acros. $\mathrm{NH}_{4} \mathrm{Cl}$ (>99\%) was purchased from Acros Organics (Noisy-le-Grand, France), technical grade $\mathrm{MgSO}_{4}$ from Carlo Erba (Val de Reuil, France), $\mathrm{CaCl} 2$ from Prolabo, and methanol ( $\geq 99.8 \%$ ), dichloromethane (DCM, $\geq 99.9 \%$ ), dimethylformamide (DMF, $\geq 99.8 \%$ ), ethanol, diethyl ether $\left(\mathrm{Et}_{2} \mathrm{O}, \geq 99.8 \%\right.$ ), acetone ( $\left.\geq 99.5 \%\right)$, amicon ultra centrifugal filter units (Ultra-15, $\left.10 \mathrm{kDa}\right)$ were purchased from Sigma Aldrich. Spectra/Por® dialysis tubes (cut-off, 6000-8000 Da or 100-500 Da) were obtained from Spectrum Labs.

\subsection{Characterizations}

NMR spectroscopy analyses were conducted at room temperature using an AMX300 Bruker spectrometer operating at $300 \mathrm{MHz}$. Deuterated chloroform $\left(\mathrm{CDCl}_{3}\right)$ and deuterated dimethyl sulfoxide $\left(\mathrm{DMSO}_{d \sigma}\right)$ were used as solvents, chemical shifts were expressed in ppm with respect to tetramethylsilane (TMS). Diffusion ordered spectroscopy (DOSY) experiments were performed on a Bruker Avance III spectrometer operating at $600 \mathrm{MHz}$, using $\mathrm{DMSO}_{d 6}$ as solvent.

Size exclusion chromatography (SEC) was performed on a Viscoteck GPC-Max VE 2001 equipment fitted with a $2 \times 30 \mathrm{~cm}$ long $5 \mu \mathrm{m}$ mixed C PLgel columns and coupled with VE 
$3580 \mathrm{RI}$ detector and VE $3210 \mathrm{UV} / \mathrm{Vis}$ detector. The mobile phase was THF at $1 \mathrm{~mL} / \mathrm{min}$ flow rate at $30^{\circ} \mathrm{C}$. Typically, polymer $(10 \mathrm{mg})$ was dissolved in THF $(2 \mathrm{~mL})$ and the resulting solution was filtered through a $0.45 \mu \mathrm{m}$ Millipore filter before injection of $20 \mu \mathrm{L}$ of filtered solution. The number average molecular weight $\left(M_{n}\right)$ and the dispersity $(\nexists)$ of the polymers were expressed according to calibration using polystyrene standards.

Dynamic light scattering (DLS) measurements were carried out with a Malvern Instrument Nano-ZS equipped with a He-Ne laser $(\lambda=632.8 \mathrm{~nm})$. Polymer solutions at $1.0 \mathrm{mg} / \mathrm{mL}$ were filtered through a $0.45 \mu \mathrm{m}$ PTFE microfilter before measurements. The correlation function was analyzed via the general purpose method (NNLS) to obtain the distribution of diffusion coefficients (D) of the solutes. The apparent equivalent hydrodynamic diameter $\left(\mathrm{D}_{H}\right)$ was determined from the cumulant method using the Stokes-Einstein equation. Mean values and standard deviations were obtained from triplicate runs measured at $25^{\circ} \mathrm{C}$.

UV-spectrometry was performed on a Perkin-Elmer Precisely Lambda 35 spectrometer, with $1 \mathrm{~cm}$ optical path quartz cuvettes.

\subsection{Synthesis of FITC-labeled PCL-g-(PEG-cRGD)}

Synthesis of cRGD-PEG-SH

cRGD-PEG-NH $\mathrm{N}_{2}$ was kindly provided by Prof. Gilles Subra and Jérémy Ciccione. cRGDPEG-NH $2($ PEG $\mathrm{Mn}=3000 \mathrm{~g} / \mathrm{mol})$ was prepared following standard solid phase peptide synthesis on the SYNBIO3 platform. PEG immobilized solid support was used thus allowing the preparation of peptide-derivatized PEG with no trace of free PEG chains. cRGD-PEG$\mathrm{NH}_{2}(60 \mathrm{mg}, 16,6 \mu \mathrm{mol})$ was then dissolved in $1.5 \mathrm{~mL}$ of anhydrous DCM. MPA $(3 \mu \mathrm{l}, 33$ $\mu \mathrm{mol})$, DCC (3.4 mg, 18,2 $\mu \mathrm{mol})$, DMAP $(6.1 \mathrm{mg}, 5 \mu \mathrm{mol})$ dissolved in $0.5 \mathrm{~mL}$ DCM were added to the reaction mixture. After 18 hours of stirring under nitrogen the product was 
precipitated in $20 \mathrm{~mL}$ of $\mathrm{Et}_{2} \mathrm{O}$ cooled by liquid nitrogen. It was then centrifuged and washed with cold $\mathrm{Et}_{2} \mathrm{O}$ two times. The product was further purified by dialysis against methanol using dialysis membrane (MW cutoff $500 \mathrm{Da}$ ). The solvent was evaporated under reduced pressure and the product was dried under vacuum.

\section{Grafting of cRGD-PEG-SH}

PCL functionalized on the backbone with propargyl groups (PCL-yne, $8 \%$ alkyne groups with respect to $\mathrm{CL}$ units, $\overline{M n}=21300 \mathrm{~g} / \mathrm{mol} ; \mathrm{Ð}=2.4$ ) was prepared according to a previous work. ${ }^{1}$ Grafting of cRGD-PEG-SH on PCL-yne was done by thiol-yne photochemistry. Typically, PCL-yne (100 mg; $68 \mu \mathrm{mol}$ of alkyne groups) and cRGD-PEG-SH (51 mg; $13.6 \mu \mathrm{mol})$ were dissolved in $2 \mathrm{~mL}$ DMF in a Schlenk flask (A) (Table 1, entry 1). In parallel, DMPA (35 mg; $136 \mu \mathrm{mol}$ ) was dissolved in $0.5 \mathrm{~mL}$ DMF in another Schlenk flask covered by aluminum foil. The 2 flasks were closed by septums after purging with argon for $10 \mathrm{~min}$. Following the addition of DMPA (25\% of total amount) to (A) under nitrogen, the reaction medium was irradiated with UV light. Reaction was carried out for 2 hours under constant stirring and constant UV light irradiation (Dymax Bluewave ${ }^{\circledR} 200,100 \mathrm{~mW} / \mathrm{cm}^{2}$ ) and DMPA was added by successive additions ( 3 times) at fixed intervals over the reaction time. The reaction mixture was purified using a mixture of water/DMF (50:50) by a centrifugal filter unit (MW cutoff $10000 \mathrm{Da}$ ). The solvent was evaporated under reduced pressure and the copolymer was dried under vacuum. ${ }^{1} \mathrm{H}$ NMR $\left(300 \mathrm{MHz} ; \mathrm{CDCl}_{3}\right): \delta(\mathrm{ppm})=$ PCL backbone $4.0\left(2 \mathrm{H}, \mathrm{CH}_{2^{-}}\right.$ O), $2.3\left(2 \mathrm{H}, \mathrm{C}(\mathrm{O}) \mathrm{CH}_{2}\right), 1.6\left(4 \mathrm{H}, \mathrm{C}(\mathrm{O}) \mathrm{CH}_{2}-\mathrm{CH}_{2}-\mathrm{CH}_{2}-\mathrm{CH}_{2}-\mathrm{CH}_{2}-\mathrm{O}\right), 1.3\left(2 \mathrm{H}, \mathrm{C}(\mathrm{O}) \mathrm{CH}_{2}-\right.$ $\left.\mathrm{CH}_{2}-\mathrm{CH}_{2}-\mathrm{CH}_{2}-\mathrm{CH}_{2}-\mathrm{O}\right)$; PEG side chains $3.6\left(4 \mathrm{H}, \mathrm{CH}_{2} \mathrm{CH}_{2} \mathrm{O}\right)$. 
Following the functionalization with cRGD-PEG chains, in order to further hydrophilize the graft copolymers, PEG-SH (PEG Mw = $2000 \mathrm{~g} / \mathrm{mol}$ ) was synthesized and grafted on propargylated PCL-g-PEG-RGD according to the conditions used in our previous work. ${ }^{2}$

${ }^{1} \mathrm{H}$ NMR $\left(300 \mathrm{MHz} ; \mathrm{CDCl}_{3}\right): \delta(\mathrm{ppm})=$ PCL backbone $4.0\left(2 \mathrm{H}, \mathrm{CH}_{2}-\mathrm{O}\right), 2.3\left(2 \mathrm{H}, \mathrm{C}(\mathrm{O}) \mathrm{CH}_{2}\right)$, $1.6\left(4 \mathrm{H}, \mathrm{C}(\mathrm{O}) \mathrm{CH}_{2}-\mathrm{CH}_{2}-\mathrm{CH}_{2}-\mathrm{CH}_{2}-\mathrm{CH}_{2}-\mathrm{O}\right), 1.3\left(2 \mathrm{H}, \mathrm{C}(\mathrm{O}) \mathrm{CH}_{2}-\mathrm{CH}_{2}-\mathrm{CH}_{2}-\mathrm{CH}_{2}-\mathrm{CH}_{2}-\mathrm{O}\right)$; PEG side chains $4.2\left(2 \mathrm{H}, \mathrm{CH}_{2} \mathrm{COO}\right), 3.6\left(4 \mathrm{H}, \mathrm{CH}_{2} \mathrm{CH}_{2} \mathrm{O}\right), 3.3\left(3 \mathrm{H}, \mathrm{OCH}_{3}\right), 2.8(2 \mathrm{H}$, $\left.\mathrm{CH}_{2} \mathrm{SCH}_{2}\right), 2.6\left(2 \mathrm{H}, \mathrm{COOCH}_{2}\right)$.

\section{FITC-labeled PCL-g-(PEG-cRGD)}

In a typical experiment, PCL-g-(PEG-cRGD) copolymer $(110 \mathrm{mg}$, including $50 \mathrm{mg}$ of PCL backbone, ca. $34 \mu \mathrm{mol}$ of initial alkyne groups) and Cys (116 mg, 30 eq. with respect to initial alkyne groups) were dissolved in $2 \mathrm{~mL}$ DMF in a Schlenk flask (Table 2, entry 3). In parallel, DMPA (25 mg, 3 eq. with respect to initial alkyne groups) was dissolved in $0.5 \mathrm{~mL}$ DMF in another Schlenk flask covered by aluminum foil. The 2 flasks were closed by septums after purging with argon for $10 \mathrm{~min}$. The thiol-yne reaction was run as described above. The reaction mixture was purified by dialysis against water using dialysis membrane (MW cutoff $10000 \mathrm{Da})$. The cysteamine-functional copolymer was isolated after freeze-drying.

Cysteamine-functional copolymer $(87 \mathrm{mg})$ was then dissolved in $7 \mathrm{~mL}$ of anhydrous ethanol and N,N-diisopropylethylamine (DIPEA) $(28 \mu \mathrm{l})$ was added. FITC (42 $\mathrm{mg}, 11 \mathrm{mmol})$ was dissolved in $4 \mathrm{~mL}$ of dry acetone and added to the copolymer solution. The mixture was covered by aluminum foil and stirred during the night at room temperature. After evaporation of acetone, the FITC-labeled copolymer was purified by dialysis against water by using a centrifugal filter unit (MW cutoff 10000 Da). FITC-labeled PCL-g-(PEG-cRGD) was isolated after freeze-drying. FITC content was assessed by UV/vis spectrometry at $497 \mathrm{~nm}$. Quantification was performed with respect to a calibration curve of FITC in acetone. 


\subsection{Synthesis of FITC-labeled PCL-g-(MMPcp-PEG)}

FITC-labeled PCL

PCL-yne (800 mg; $0.55 \mathrm{mmol}$ alkyne groups) was dissolved with Cys (31 mg; $0.27 \mathrm{mmol})$ in $3 \mathrm{~mL}$ DMF in a Schlenk flask. Similarly, DMPA (140 mg, $0.55 \mathrm{mmol})$ was dissolved in $1 \mathrm{~mL}$ DMF in a Schlenk flask covered by aluminum foil. The 2 flasks were closed by septums after purging with argon for $10 \mathrm{~min}$. The thiol-yne reaction medium was irradiated for 2 hours with UV light (Dymax Bluewave ${ }^{\circledR}$ 200, $100 \mathrm{~mW} / \mathrm{cm}^{2}$ ) and DMPA was added by successive additions (4 times) at fixed intervals over the reaction time. The solution was concentrated under vacuum and precipitated in cold methanol before drying of the copolymer under vacuum.

The copolymer was then dissolved with DIPEA $(139 \mu \mathrm{l} ; 0.82 \mathrm{mmol})$ in $6 \mathrm{~mL}$ of anhydrous DMF. In parallel, FITC (159 mg; $0.41 \mathrm{mmol}$ ) was dissolved in $2 \mathrm{~mL}$ of anhydrous DMF and added to copolymer solution. The mixture was covered by aluminum foil and stirred for 3 hours at room temperature. The solution was purified by dialysis against DMF using a centrifugal filter unit (MW cutoff $3500 \mathrm{Da}$ ). The solvent was evaporated under reduced pressure and the copolymer was dried under vacuum.

Synthesis of FITC-labeled PCL-g-(MMPcp-PEG)

PEG-MMPcp-SH was kindly provided by Prof. Gilles Subra and Jérémy Ciccione. PEGMMPcp-SH (PEG Mn = $750 \mathrm{~g} / \mathrm{mol}$; MMP cleavable peptide = GPQGLAGQC) was prepared following standard solid phase peptide synthesis on the SYNBIO3 platform. FITC-labeled PCL-g-(MMPcp-PEG) was obtained by thiol-yne reaction of FITC-labeled PCL and PEGMMPcp-SH. Typically, FITC-labeled PCL (20 mg) and PEG-MMPcp-SH (140 mg; 6 eq with respect to initial alkyne groups) were dissolved in 1.5 mL DMF in a Schlenk flask. Similarly, DMPA (10 mg, 4 eq. with respect to initial alkyne groups) was dissolved in $0.5 \mathrm{~mL} \mathrm{DMF}$ in a 
Schlenk flask covered by aluminum foil. The 2 flasks were closed by septums after purging with argon for $10 \mathrm{~min}$. The thiol-yne reaction medium was done as described above. The reaction mixture was purified by dialysis against water by a centrifugal filter unit (MW cutoff $10000 \mathrm{Da})$. The copolymer was finally freeze-dried.

\subsection{Copolymer notations}

For sake of clarity, the following notations are used to identify the various copolymers:

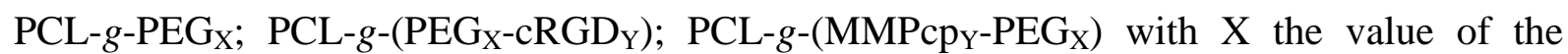
EG/CL ratio representing the hydrophilic/hydrophobic balance of the copolymer and $\mathrm{Y}$ the number of cRGD or MMPcp moieties per copolymer.

\subsection{Preparation of nanoaggregates}

\section{Preparation of targeting nanoaggregates}

Nanoaggregates were prepared by the self-assembly method according to our previous work. ${ }^{2}$ In brief, selected PCL- $g$-(PEG $\left.{ }_{X}-\mathrm{cRGD}_{\mathrm{Y}}\right)(10 \mathrm{mg})$ was dissolved in $2 \mathrm{~mL}$ of acetone, and then poured into $10 \mathrm{~mL}$ of PBS. Nanoaggregates spontaneously formed following the slow evaporation of acetone under atmospheric pressure.

Preparation of MMP sensitive nanoaggregates

In brief, for blank nanoaggregates selected PCL- $g$-(MMPcp $\left.{ }_{Y}-\mathrm{PEG}_{\mathrm{X}}\right)(5 \mathrm{mg})$ and PCL- $g$-PEG ( $5 \mathrm{mg}, \mathrm{PEG}_{2 \mathrm{k}}$ side chains, $\mathrm{EG} / \mathrm{CL}=4.2$ ) were dissolved in $2 \mathrm{~mL}$ of acetone, and then poured into 10 $\mathrm{mL}$ of PBS. The slow evaporation of acetone under atmospheric pressure and then under vacuum allows the formation of nanoaggregates.

Curcumin loaded nanoaggregates were also prepared by the self-assembly method. Typically, curcumin (1.4 mg), PCL-g-(MMPcp $\left.{ }_{Y}-\mathrm{PEG}_{\mathrm{X}}\right)(5 \mathrm{mg})$ and PCL- $g$-PEG (5 mg, $\mathrm{PEG}_{2 \mathrm{k}}$ side chains, $\mathrm{EG} / \mathrm{CL}=4.2)$ were dissolved in $0.5 \mathrm{~mL}$ acetone. Then $4.5 \mathrm{~mL}$ of PBS were added. The mixture was stirred one hour using an Ultra-Turrax stirrer $(8000 \mathrm{rpm})$. The remaining acetone was 
evaporated under vacuum. The solution was then centrifuged for $10 \mathrm{~min}$ at $3600 \mathrm{rpm}$ and $20^{\circ} \mathrm{C}$ before filtration through a $0.45 \mu \mathrm{m}$ filter to eliminate the unloaded drug.

\section{Determination of drug loading and encapsulation efficiency}

Drug loading (DL) was determined by UV/Vis spectrophotometry at $425 \mathrm{~nm}$. Quantification was performed with respect to a calibration curve of curcumin in acetone/water (20:80). The DL content was calculated based on the following formulae:

$\operatorname{DL}(\%)=100 \times\left(M_{\mathrm{C}}\right) /\left(M_{\mathrm{P}}+M_{\mathrm{C}}\right)$

With $M_{\mathrm{C}}=$ mass of curcumin in micelles and $M_{\mathrm{P}}=$ mass of copolymer.

\subsection{Quantification of fluorescently labeled blank micelles uptake to the cells by flow}

\section{cytometry}

PC-3 (human prostate adenocarcinoma cell line, (ATCC)), or LNCaP (human prostate adenocarcinoma cell line, (ATCC)), cells were seeded at $5 \times 10^{4}$ per well into a 24 -well plate one day before incubation with blank micelles labeled with FITC. Micelles at four different concentrations $(1,10,50$ and $100 \mu \mathrm{g} / \mathrm{mL})$ were incubated with the cells for 0.5 or $2 \mathrm{~h}$ in a $5 \%$ $\mathrm{CO}_{2}$ atmosphere at $37{ }^{\circ} \mathrm{C}$. Then the cells were detached from the bottom of the well by incubation in detaching solution $(0.5 \%$ BSA, 10 mM EDTA, 100 mM NaCl, 20 mM HEPES, $\mathrm{pH}$ 7.4), centrifuged and resuspended in $0.5 \mathrm{~mL}$ of PBS- $0.5 \%$ BSA with $5 \mu \mathrm{g} / \mathrm{mL}$ of Hoechst 33258. Hoechst 33258 was used to label dead cells. The median of FITC fluorescence intensity of live cells were evaluated depending on the incubation in different concentration of micelles. For the comparison of binding efficacy the intensity of the signal was recalculated per $1 \%$ of FITC on the micelles. The samples were measured and analyzed by FACS Verse (Becton Dickinson) and FlowJo software. The binding efficacy of micelles was evaluated at two incubation times in duplicates. Cells without micelles incubation were used as negative control. 


\subsection{Cytotoxicity assays}

Transfected HEK293- $\beta 3$ cells were procured from Jean-Luc COLL's lab, Albert Bonniot Institute, Grenoble. The human embryonic HEK293 has been stably transfected with $\beta 3$ thus forming the HEK293- $\beta 3$ cell line. HEK293- $\beta 3$ cells overexpressed integrin $\beta 3$ chain lead to an increased level of MMP-2 and MMP-9 expression. ${ }^{3}$ Cells were maintained in DMEM supplemented with $10 \%$ FBS and $1 \%$ penicillin / streptomycin at $37^{\circ} \mathrm{C}$ in a humidified incubator containing $5 \% \mathrm{CO}_{2}$.

The cytotoxicity of the nanoaggregates was assessed using Prestoblue ${ }^{\circledR}$ Cell viability reagent (Invitrogen). For this assay, cells were seeded at $4.10^{4}$ cells per well into a 24 -well plate and allowed to attach overnight. They were then treated with 7 and $15 \mu \mathrm{g} / \mathrm{mL}$ of curcumin encapsulated in the nanoaggregates (dissolved in PBS) for $24 \mathrm{~h}$ and $48 \mathrm{~h}$. Appropriate equivalent amounts of nanoparticles without curcumin were run simultaneously. Also medium containing equivalent amounts of PBS or medium only were used as a control (Figure S4). Cell viability was measured using Prestoblue ${ }^{\circledR}$ Cell viability reagent according to manufacturer's instruction. Briefly, $10 \%$ of Prestoblue ${ }^{\circledR}$ was diluted into cell growth medium. When added to cells, the reagent is modified by the reducing environment of the viable cells and turns red in color, becoming highly fluorescent. After incubation time, supernatant was transferred to a 96-well plate and the fluorescence was measured at 560/590nm using a microplate reader (PerkinElmer, Victor3V). Data are expressed as means $\pm \mathrm{SD}$ and correspond to measurements in triplicate.

\section{References}

[1]. A. Leroy, A. Al Samad, X. Garric, S. Hunger, D. Noël, J. Coudane, B. Nottelet, RSC Adv. 2014, 4, 32017.

[2] A. Al Samad, A. Bethry, E. Koziolova, M. Netopilik, T. Etrych, Y. Bakkour, J. Coudane, F. El Omar, B. Nottelet, J. Mater. Chem. B. 2016, 4, 6228. 
[3] C. H. F. Wenk, V. Josserand, P. Dumy, J.-L. Coll, D. Boturyn, Org. Biomol. Chem. 2013, 11,448 . 


\section{Supplementary results and discussions}<smiles>CCOCCNC(=O)CCS</smiles><smiles>COC(C)(C)CCC(C)(C)CC(=O)NCC(=O)N1CCCC1C(=O)N[C@@H](CCC(N)=O)C(=O)NCC(=O)N[C@@H](CC(C)C)C(=O)N[C@@H](C)C(=O)NCC(=O)N[C@@H](CCC(N)=O)C(=O)N[C@@H](CS)C(=O)O</smiles>

Scheme S1. Structure of cRGD-PEG-SH and of PEG-MMPcp 

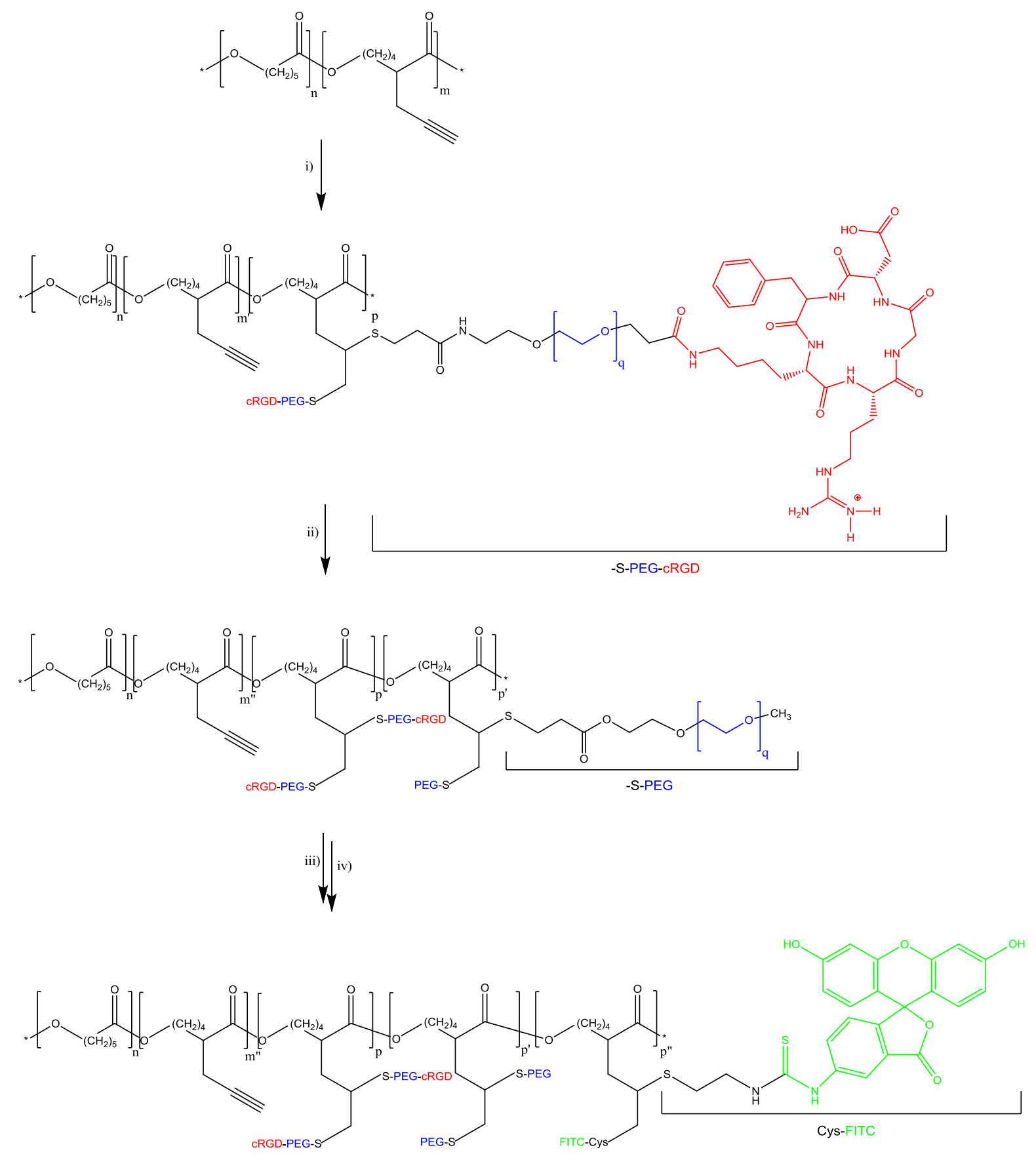

Scheme S2. Synthesis of FITC-labeled PCL-g-(PEG-cRGD) copolymers with i) thiol-yne photoaddition of cRGD-PEG-SH, ii) thiol-yne photoaddition of PEG-SH, iii) thiol-yne photoaddition of cysteamine and iv) coupling of FITC. (See experimental part for detailed reaction conditions) 

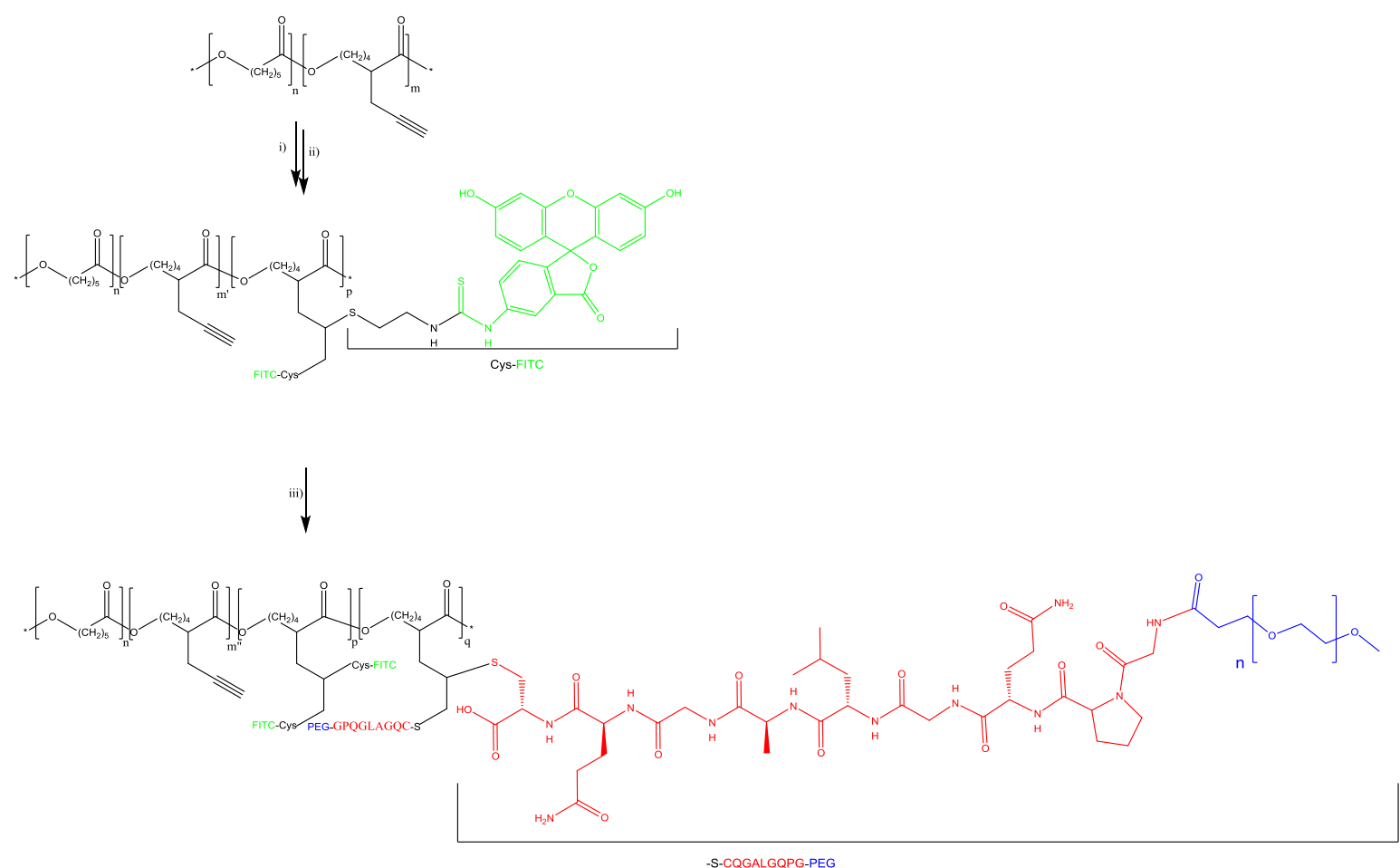

Scheme S3. Synthesis of FITC-labeled PCL-g-(MMPcp-PEG) sheddable copolymers with i) thiol-yne photoaddition of cysteamine, ii) coupling of FITC and iii) thiol-yne photoaddition of PEG-GPQGLAGQC-SH. (See experimental part for detailed reaction conditions) 
Table S1. Coupling of $\mathrm{PEG}_{3 \mathrm{k}}-\mathrm{cRGD}$ building block to PCL-yne.

\begin{tabular}{|c|c|c|c|c|}
\hline Copolymer & $\begin{array}{l}\text { CRGD / } \\
\text { alkyne (eq.) }\end{array}$ & $\begin{array}{l}\text { DMPA / } \\
\text { alkyne (eq.) }\end{array}$ & $\begin{array}{l}\text { Number of CRGD } \\
/ \mathrm{PCL}^{\mathrm{a}}\end{array}$ & $\mathrm{EG} / \mathrm{CL}^{\mathrm{a}}$ \\
\hline PCL-g-(PEG-RGD 0.4$)$ & 0,2 & 2 & 0,43 & 0.2 \\
\hline PCL-g-(PEG-RGD 1.7$)$ & 1 & 3 & 1,70 & 0.7 \\
\hline
\end{tabular}

${ }^{\mathrm{a}}$ calculated from the peak integrations of ${ }^{1} \mathrm{H}-\mathrm{NMR}$ spectra.

Table S2. Characterization of the PCL-g-(PEG-cRGD) copolymers prepared by iterative strategy

\begin{tabular}{|c|c|c|c|c|c|}
\hline Entry & Copolymers & $\begin{array}{c}\text { FITC }^{a} \\
\text { (mol\%) }\end{array}$ & $\begin{array}{c}\mathrm{Mn}^{\mathrm{b}} \\
(\mathrm{g} / \mathrm{mol})\end{array}$ & $\boldsymbol{\Xi}^{\mathrm{b}}$ & $\mathrm{EG} / \mathrm{CL}^{\mathrm{C}}$ \\
\hline 1 & PCL-g-(PEG $\left.2.3^{-}{ }^{-C R G D} 0.4\right)$ & 2.5 & 23800 & 1.8 & 2.3 \\
\hline 2 & PCL-g-(PEG $\left.{ }_{3.1}-\mathrm{CRGD}_{0.4}\right)$ & 3 & 23500 & 1.6 & 3.1 \\
\hline 3 & PCL-g-(PEG $\left.{ }_{2.4}-\mathrm{CRGD}_{1.7}\right)$ & 9 & 19400 & 1.7 & 2.4 \\
\hline 4 & PCL-g-PEG ${ }_{3.2}$ & 3 & 25300 & 2.2 & 3.2 \\
\hline
\end{tabular}

${ }^{\text {a }}$ calculated from the UV/vis spectrometry at $497 \mathrm{~nm}$.

${ }^{\mathrm{b}}$ calculated from SEC analyses in THF using polystyrene standards

${ }^{c}$ calculated from the peak integrations of ${ }^{1} \mathrm{H}-\mathrm{NMR}$ spectra. 
Table S3. Characterization of PCL-g-(PEG-cRGD) nanoaggregates

\begin{tabular}{|c|c|c|c|c|c|}
\hline Entry & Copolymers & $\begin{array}{c}\text { Size }^{\mathrm{a}} \\
\left(\mathrm{D}_{H}, \mathrm{~nm}\right)\end{array}$ & $\begin{array}{c}\text { Size }^{\mathrm{b}} \\
\left(\mathrm{D}_{H}, \mathrm{~nm}\right)\end{array}$ & $\begin{array}{c}\text { Size } \\
\text { Z-average } \\
\left(\mathrm{D}_{H}, \mathrm{~nm}\right)\end{array}$ & PDI \\
\hline 1 & PCL-g-(PEG $\left.2.3{ }^{-C R G D_{0.4}}\right)$ & $\begin{array}{l}26 \pm 4(20 \%) \\
127 \pm 5(80 \%)\end{array}$ & $19 \pm 2$ & $79 \pm 1$ & 0.29 \\
\hline 2 & PCL-g-(PEG $\left.3.1-C R G D_{0.4}\right)$ & $\begin{array}{l}36 \pm 1(100 \%) \\
28 \pm 2(10 \%) \\
152 \pm 2(90 \%)\end{array}$ & $\begin{array}{l}16 \pm 1 \\
24 \pm 1\end{array}$ & $\begin{array}{l}36 \pm 1 \\
112 \pm 1\end{array}$ & $\begin{array}{l}0.23 \\
0.23\end{array}$ \\
\hline 4 & PCL-g-PEG 3.2 & $44 \pm 9(100 \%)$ & $16 \pm 1$ & $33 \pm 1$ & 0.30 \\
\hline
\end{tabular}

Table S4. Conditions for the synthesis of PCL-g-(MMPcp-PEG) by thiol-yne photoaddition

\begin{tabular}{|c|c|c|c|c|c|}
\hline Entry & Copolymer & $\begin{array}{l}\text { MMPcp / } \\
\text { alkyne } \\
\text { (eq.) }\end{array}$ & $\begin{array}{c}\text { DMPA / } \\
\text { alkyne } \\
\text { (eq.) }\end{array}$ & $\begin{array}{c}\text { Number of } \\
\text { MMPcp / PCL }\end{array}$ & $\mathrm{EG} / \mathrm{CL}^{\mathrm{a}}$ \\
\hline 1 & PCL-g-( MMPcp $_{2.7}-$ PEG $\left._{0.4}\right)$ & 3 & 4 & 2.7 & 0.4 \\
\hline 2 & PCL-g-( $\left.\mathrm{MMPcp}_{4.0}-\mathrm{PEG}_{0.6}\right)$ & 6 & 4 & 4.0 & 0.6 \\
\hline 3 & PCL-g-(MMPcp $\left.4.7-\mathrm{PEG}_{0.7}\right)$ & 12 & 8 & 4.7 & 0.7 \\
\hline
\end{tabular}

${ }^{\mathrm{a}}$ calculated from the peak integrations of ${ }^{1} \mathrm{H}-\mathrm{NMR}$ spectra. 
Table S5. Characterization of curcumin loaded sheddable (S) and non-sheddable (NS) nanoaggregates.

\begin{tabular}{|c|c|c|c|c|c|c|c|}
\hline Name & Sheddable copolymer used ${ }^{a}$ & $\mathrm{EG} / \mathrm{CL}$ & $\begin{array}{c}\text { Drug } \\
\text { loading } \\
(\%)\end{array}$ & $\begin{array}{c}\text { Size }^{b} \\
\left(D_{H}, \mathrm{~nm}\right)\end{array}$ & $\begin{array}{c}\text { Size }^{c} \\
\left(D_{H}, n m\right)\end{array}$ & $\begin{array}{c}\text { Size } \\
\text { Z-average } \\
\left(D_{H}, \mathrm{~nm}\right)\end{array}$ & PDI \\
\hline S2.7 & PCL-g-(MMPcp $\left.2.7-\mathrm{PEG}_{0.4}\right)$ & 1.6 & 8 & $270 \pm 1$ & $14 \pm 2$ & $155 \pm 4$ & 0.4 \\
\hline S4.0 & PCL-g-(MMPcp $\left.{ }_{4.0}-\mathrm{PEG}_{0.6}\right)$ & 1.8 & 12 & $137 \pm 5$ & $7 \pm 2$ & $85 \pm 1$ & 0.3 \\
\hline S4.7 & PCL-g-(MMPcp $\left.{ }_{4.7}-\mathrm{PEG}_{0.7}\right)$ & 1.9 & 12 & $98 \pm 3$ & $11 \pm 3$ & $67 \pm 1$ & 0.3 \\
\hline NS & none & 2.0 & 12 & $172 \pm 6$ & $15 \pm 2$ & $109 \pm 4$ & 0.3 \\
\hline
\end{tabular}

${ }^{\mathrm{a}}$ Formulation with $50 \%$ wt of PCL-g-PEG (PEG ${ }_{2 \mathrm{k}}$ side chains, $\left.\mathrm{EG} / \mathrm{CL}=4.2\right)$

${ }^{\mathrm{b}}$ Mean size determined by DLS in the intensity mode

${ }^{\mathrm{c}}$ Mean size determined by DLS in the number mode 


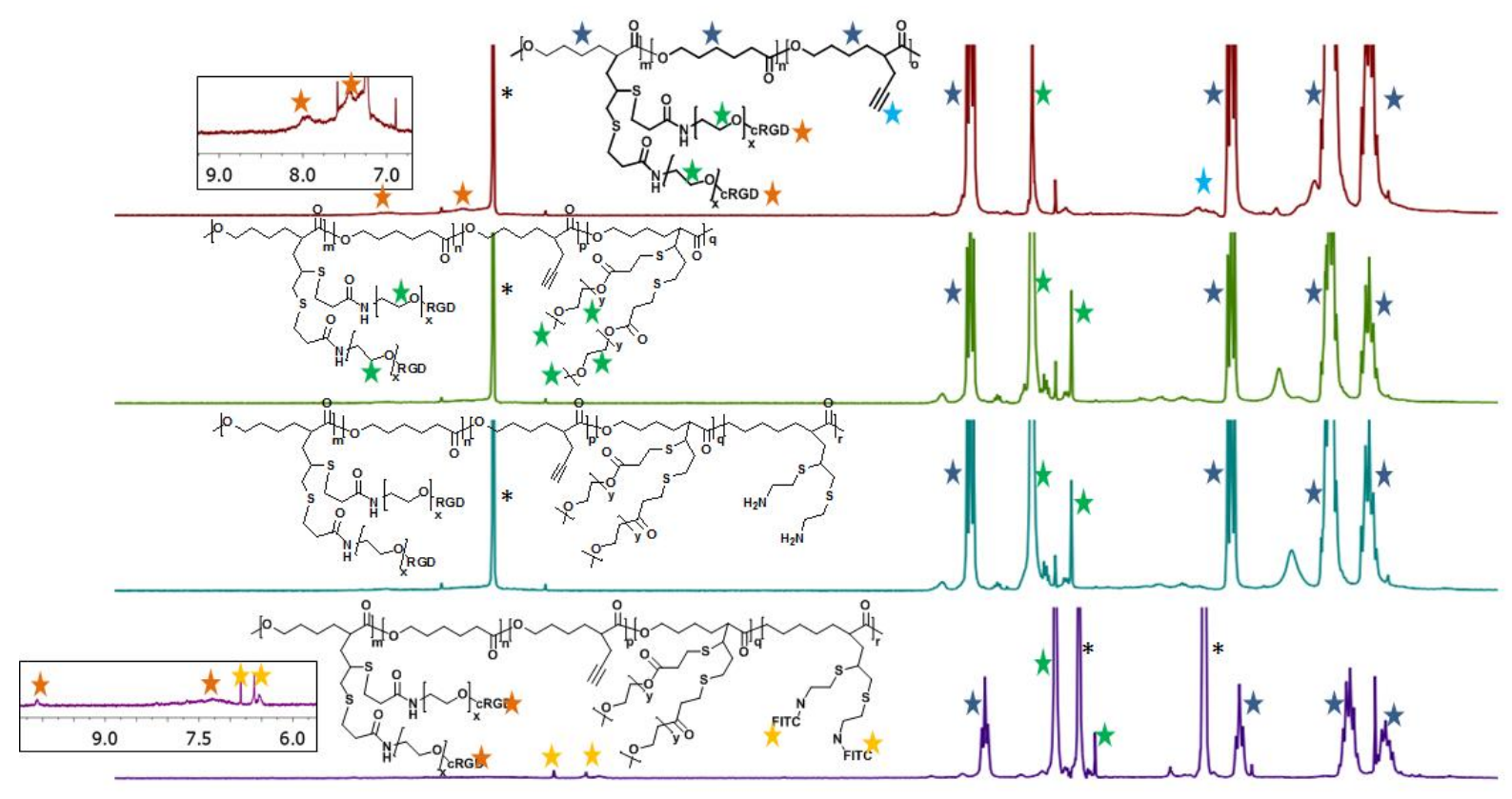

$\begin{array}{lllllllllllllllllll}9.5 & 9.0 & 8.5 & 8.0 & 7.5 & 7.0 & 6.5 & 6.0 & 5.5 & 5.0 & 4.5 & 4.0 & 3.5 & 3.0 & 2.5 & 2.0 & 1.5 & 1.0 & 0.5\end{array}$ f1 (ppm)

Figure S1. Typical ${ }^{1} \mathrm{H}$ NMR $\left(\mathrm{CDCl}_{3}\right.$ or $\left.\mathrm{DMSOd}_{6}, 300 \mathrm{MHz}\right)$ spectra of targeting PCL- $g$ (PEG-cRGD) copolymers (* correspond to solvents, purple spectra correspond to the final copolymer PCL-g-(PEG $\left.\left.2.3-\mathrm{CRGD}_{0.4}\right)\right)$ 

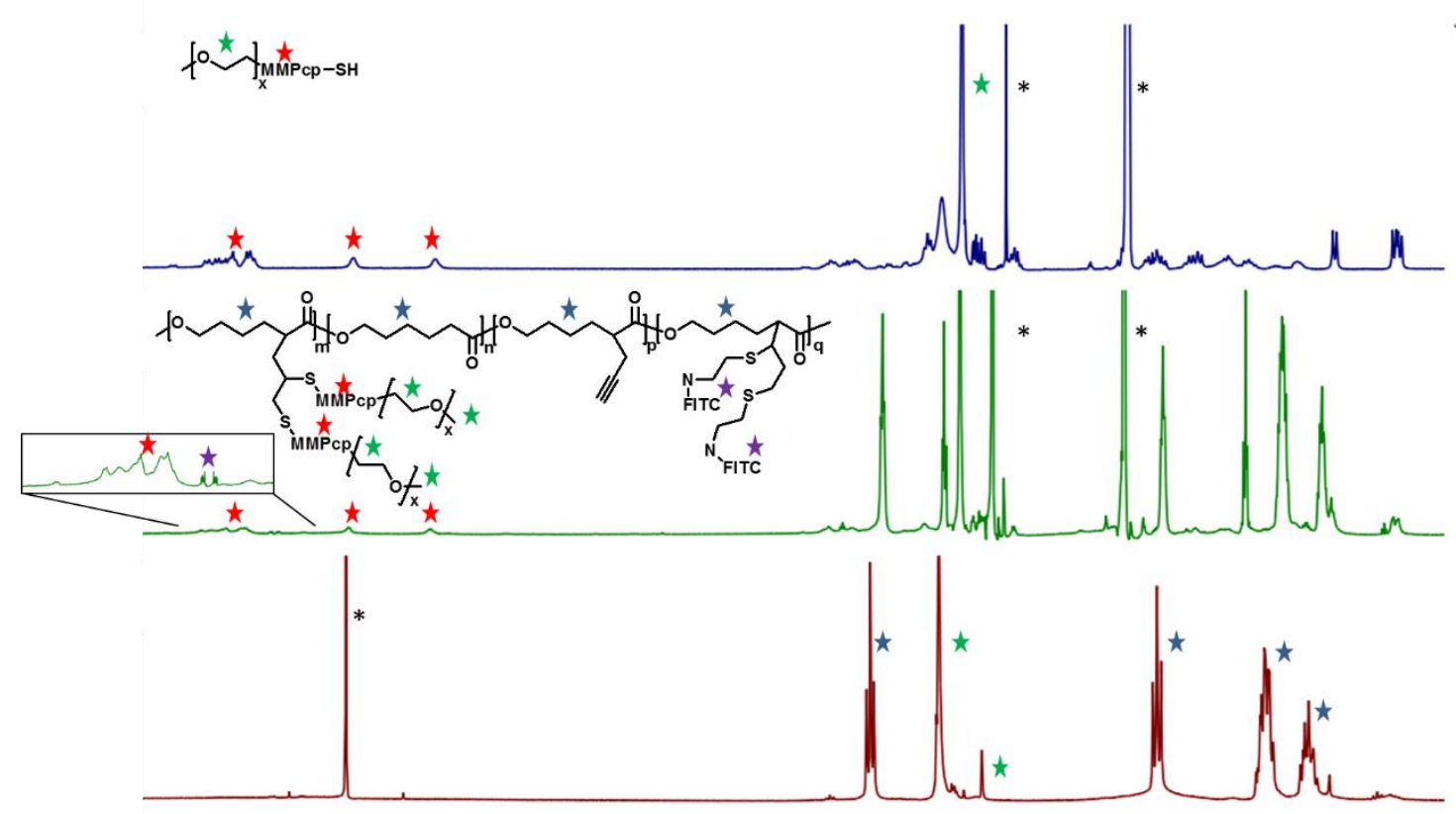

$\begin{array}{llllllllllllllll}8.0 & 7.5 & 7.0 & 6.5 & 6.0 & 5.5 & 5.0 & \begin{array}{l}4.5 \\ \mathrm{f} 1(\mathrm{ppm})\end{array} & 4.0 & 3.5 & 3.0 & 2.5 & 2.0 & 1.5 & 1.0 & 0.5\end{array}$

Figure S2. Typical ${ }^{1} \mathrm{H}$ NMR $\left(\mathrm{DMSOd}_{6}\right.$ or $\left.\mathrm{CDCl} 3,300 \mathrm{MHz}\right)$ spectra of enzyme-responsive PCL-g-(MMPcp $4.7-\mathrm{PEG})$ copolymers (* correspond to solvents, blue spectrum corresponds to MMPcp-PEG in $\mathrm{DMSOd}_{6}$, green spectrum corresponds to PCL-g-(MMPcp $\left.4.7-\mathrm{PEG}\right)$ in DMSO and red spectrum corresponds to the same copolymers in $\mathrm{CDCl}_{3}$ ). 

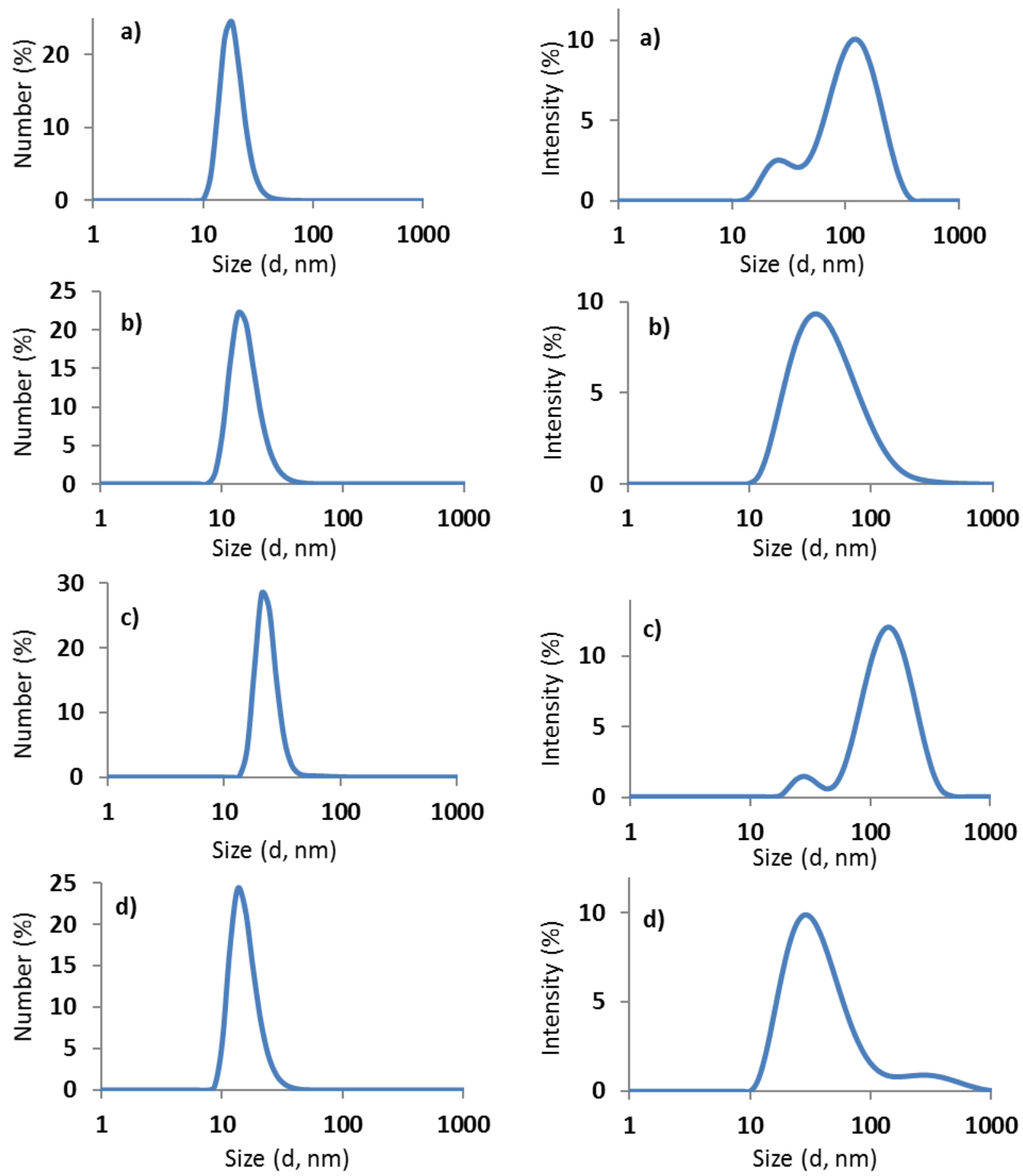

Figure S3. DLS data for PCL-g-(PEG-cRGD) DDS $(1 \mathrm{mg} / \mathrm{mL})$ with (a) PCL-g-(PEG $2.3^{-}$ cRGD 0.4 , (b) PCL-g-(PEG 3.1 -cRGD 0.4$)$, (c) PCL- $g-\left(\mathrm{PEG}_{2.4}-\mathrm{cRGD}_{1.7}\right)$ and (d) PCL- $g-\mathrm{PEG}_{3.2}$ 

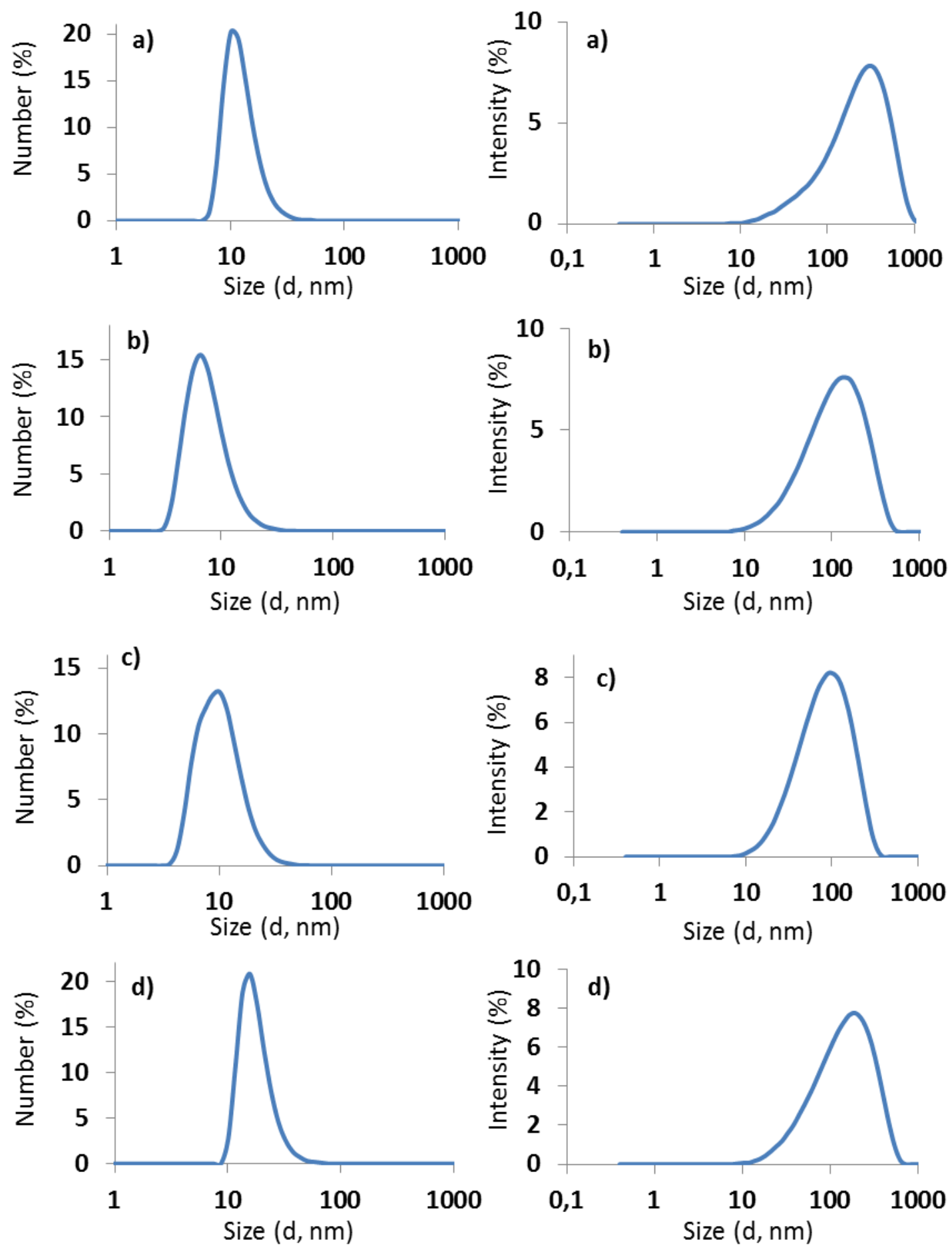

Figure S4. DLS data for curcumin-loaded PCL-g-(MMPcp-PEG) DDS (1 mg/mL, see Table S5 details on formulations) with (a) S2.7, (b) S4.0, (c) S4.7 and (d) NS. 


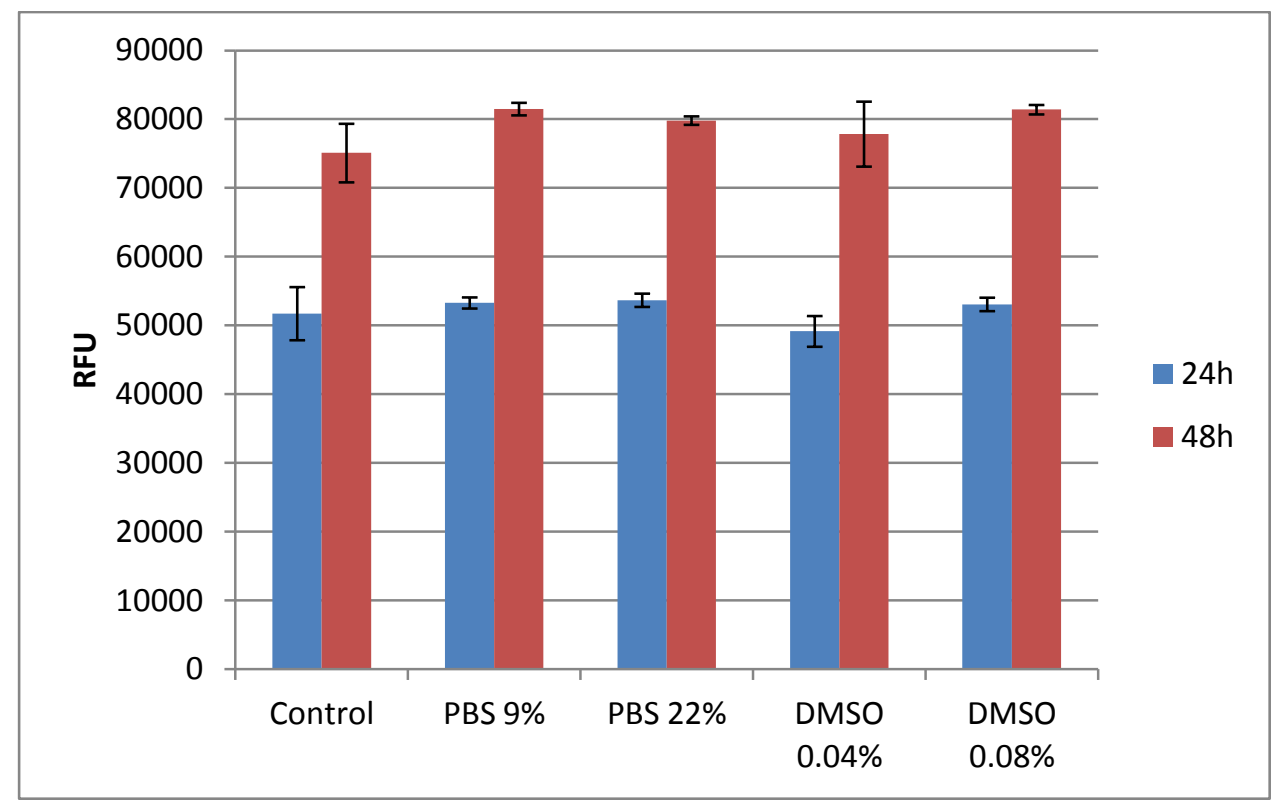

Figure S5. Viability of HEK293- $\beta 3$ cells in different media after 24 and 48 hours. Media include the culture medium (control), the culture medium supplemented with PBS (9\% and $22 \%)$ and the culture medium supplemented with DMSO (0.04\% and $0.08 \%)$ 

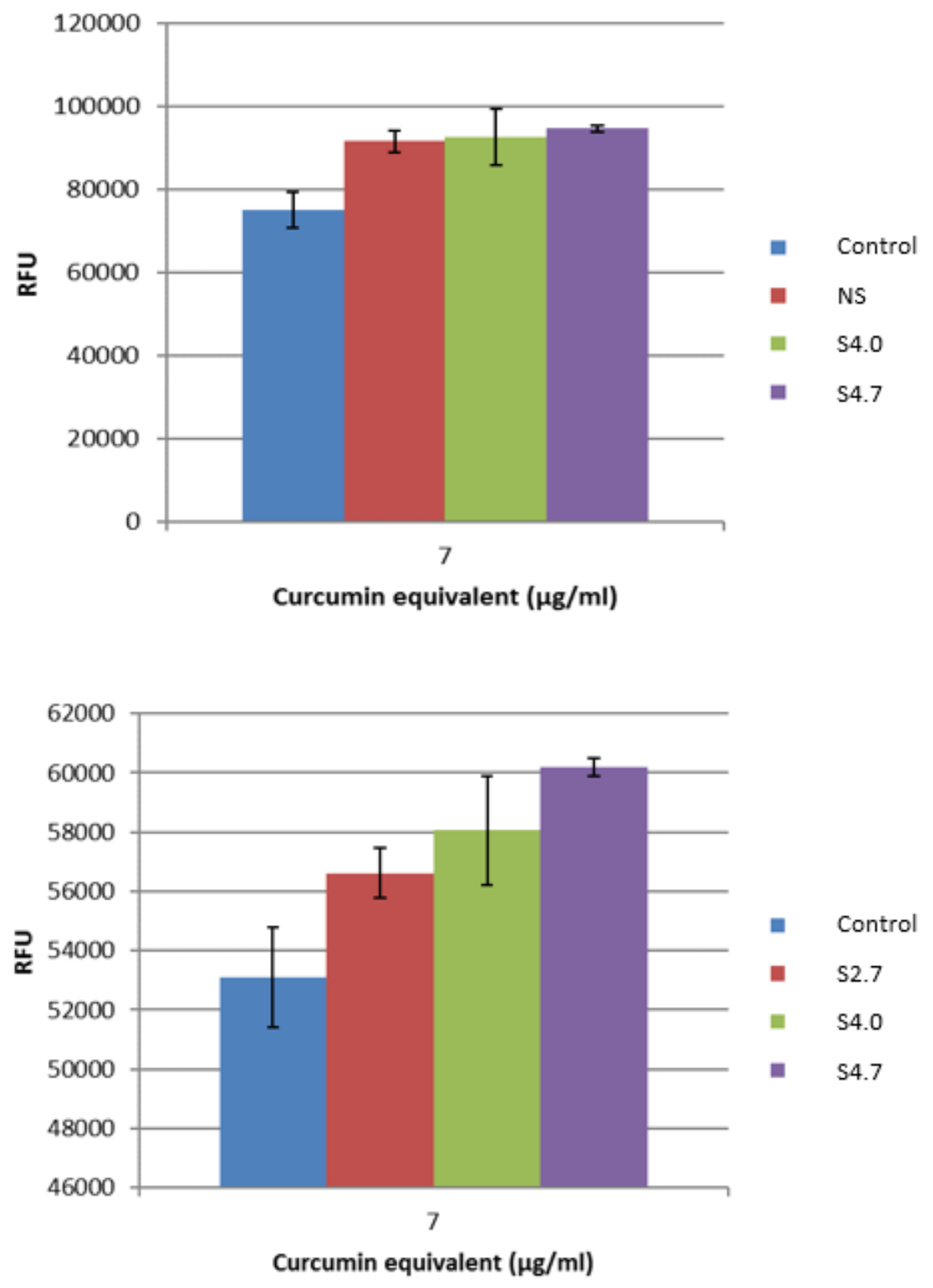

Figure S6. Viability of HEK293- $\beta 3$ cells after 48 hours in the presence of non-loaded nanoaggregates. The concentration of blank nanoaggregates used in this assay was equal to the concentration of loaded nanoaggregates used to reach curcumin concentrations of $7 \mu \mathrm{g} / \mathrm{mL}$ in the cytotoxicity assays (control corresponds to pure culture medium, top and bottom graphs correspond to two independent experiments). 

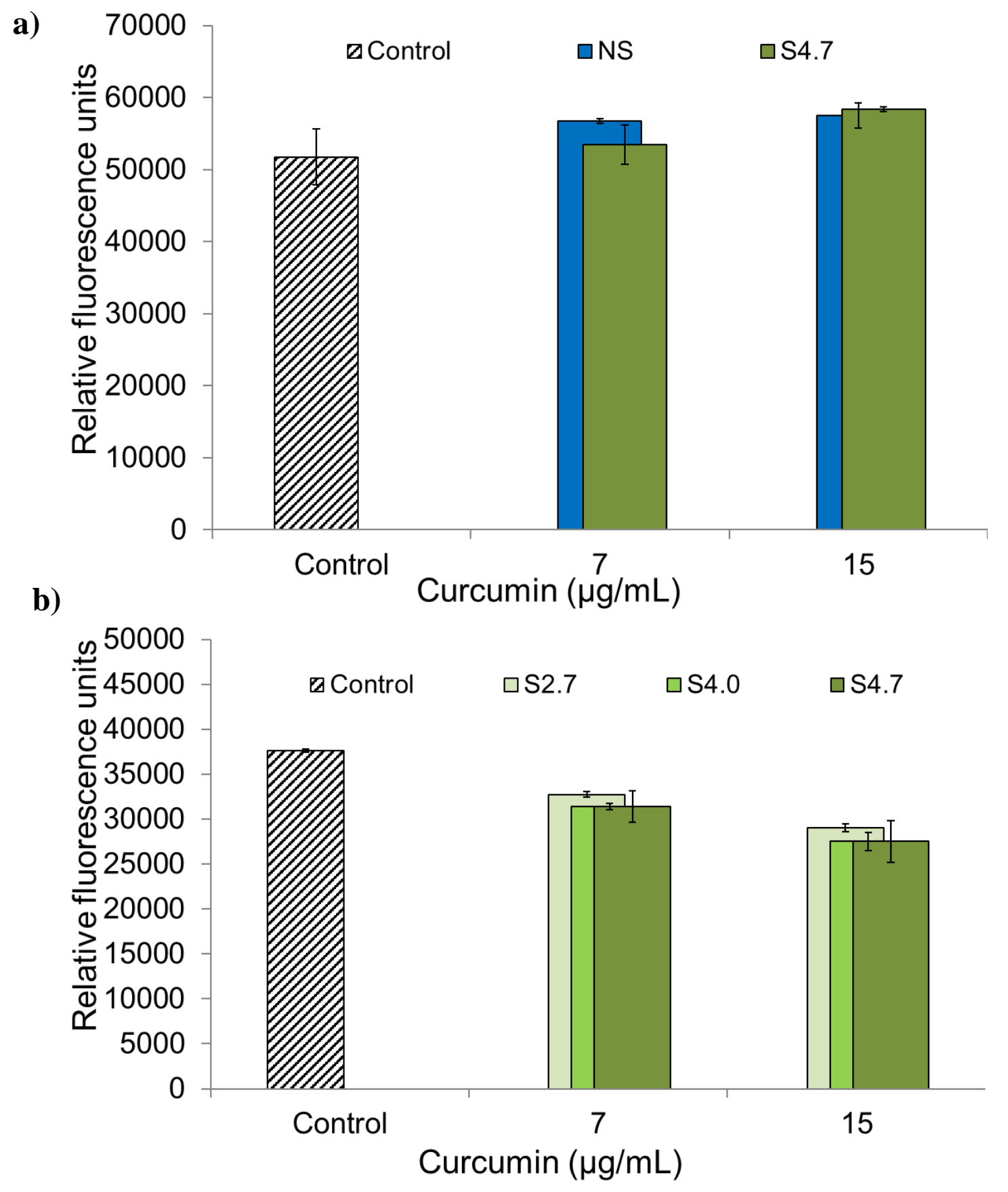

Figure S7. In vitro HEK293- $\beta 3$ cells cytotoxicity of curcumin-loaded nanoaggregates (Table S5, SI) after 24 hours with (a) non-sheddable vs. sheddable nanoaggregates, and (b) influence of the proportion of cleavable MMPcp moieties in the nanoaggregates formulation (control corresponds to culture medium without nanoaggregates and without curcumin). 


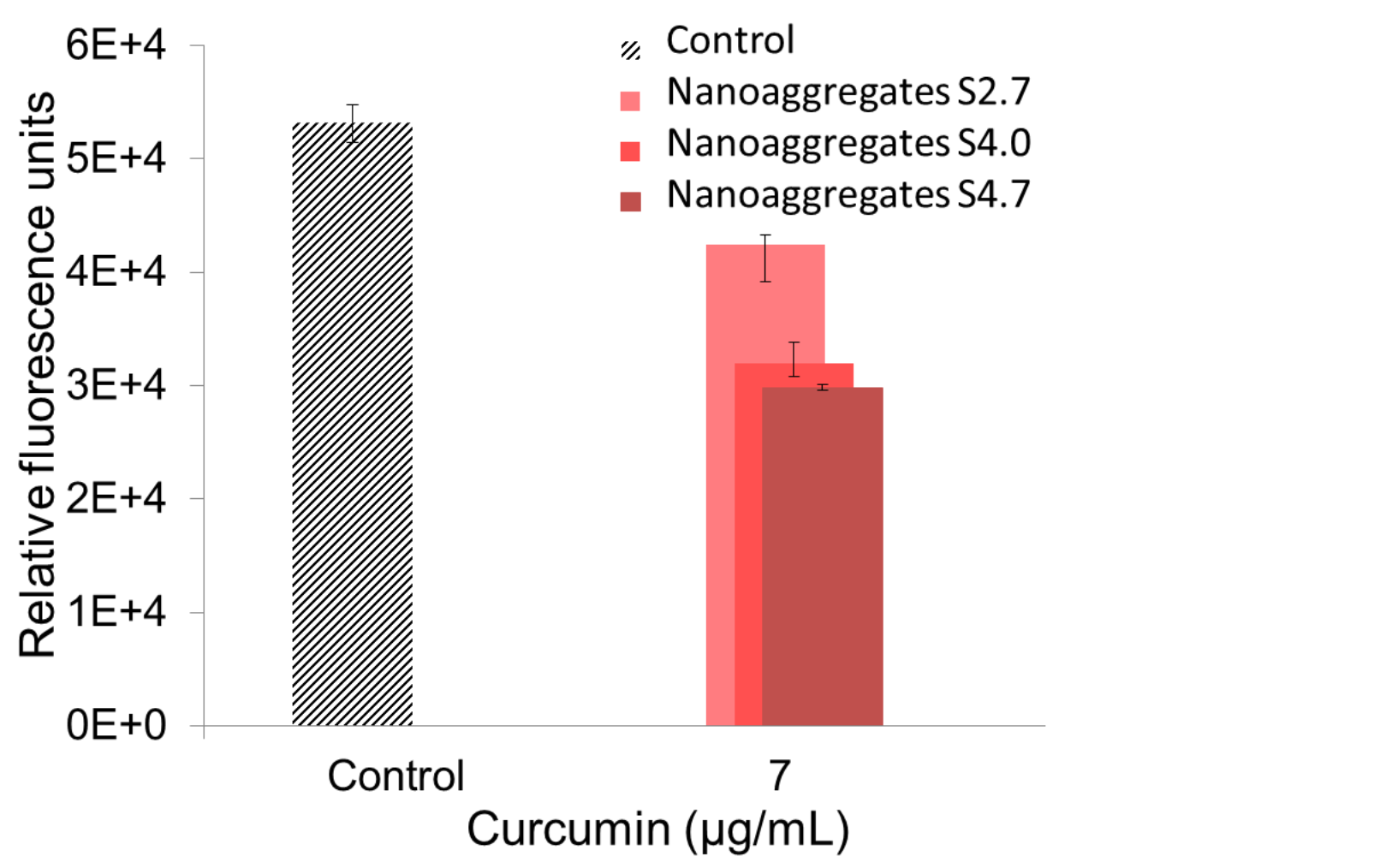

Figure S8. Influence of the proportion of cleavable MMPcp moieties in the nanoaggregates formulation on the in vitro HEK293- $\beta 3$ cells cytotoxicity of curcumin-loaded nanoaggregates (48 hours incubation, control correspond to culture medium without nanoaggregates and without curcumin). 